\title{
Entomological and parasitological impacts of indoor residual spraying with DDT, alphacypermethrin and deltamethrin in the western foothill area of Madagascar
}

\author{
Jocelyn Ratovonjato ${ }^{1 *}$, Milijaona Randrianarivelojosia ${ }^{1}$, Maroafy E Rakotondrainibe², Vaomalala Raharimanga',
} Lala Andrianaivolambo ${ }^{1}$, Gilbert Le Goff ${ }^{1,3}$, Christophe Rogier ${ }^{1}$, Frédéric Ariey ${ }^{1,4}$, Sébastien Boyer ${ }^{1}$

and Vincent Robert ${ }^{1,3}$

\begin{abstract}
Background: In Madagascar, indoor residual spraying (IRS) with insecticide was part of the national malaria control programme since the middle of the twentieth century. It was mainly employed in the highlands and the foothill areas, which are prone to malaria epidemics. Prior to a policy change foreseeing a shift from DDT to pyrethroids, a study was carried out to assess the entomological and parasitological impacts of IRS in areas with DDT or pyrethroids and in areas without IRS.

Methods: The study was carried out from October 2002 to February 2005 in three communes of the western foothill area of Madagascar. Two communes received IRS with DDT in February 2003, then IRS with pyrethroids (alphacypermethrin or deltamethrin) in February 2004. The third commune remained untreated. Mosquitoes were collected at night using human landing catches and early in the morning in resting places. Blood smears were obtained from schoolchildren and microscopically examined for Plasmodium presence.
\end{abstract}

Results: In total, 18,168 human landing mosquitoes and 12,932 resting anophelines were collected. The Anopheles species caught comprised 10 species. The main and most abundant malaria vector was Anopheles funestus (72.3\% of human-seeking malaria vectors caught indoors). After IRS had taken place, this species exhibited a lower human biting rate and a lower sporozoite index. Overall, 5,174 blood smears were examined with a mean plasmodic index of $19.9 \%$. A total of four Plasmodium species were detected. Amongst tested school children the highest plasmodial index was $54.6 \%$ in the untreated commune, compared to $19.9 \%$ in the commune sprayed with DDT and $11.9 \%$ in the commune sprayed with pyrethroid. The highest prevalence of clinical malaria attacks in children present at school the day of the survey was 33\% in the untreated commune compared to $8 \%$ in the areas which received IRS.

Conclusion: In terms of public health, the present study shows (1) a high efficacy of IRS with insecticide, (2) a similar efficacy of DDT and pyrethroid and (3) a similar efficacy of alphacypermethrin and deltamethrin. The use of IRS with DDT and pyrethroid greatly decreased the vector-human contact, with an associated decrease of the plasmodial index. However malaria transmission did not reach zero, probably due to the exophilic host-seeking and resting behaviours of the malaria vectors, thus avoiding contact with insecticide-treated surfaces indoors. The study highlights the strengths and weaknesses of the IRS implementation and the need for complementary tools for an optimal vector control in Madagascar.

Keywords: Indoor residual spraying, DDT, Pyrethroids, Anopheles funestus, Anopheles arabiensis, Anopheles mascarensis, Plasmodium falciparum, Malaria

\footnotetext{
* Correspondence: ratov@pasteur.mg

'Institut Pasteur de Madagascar, Ambatofotsikely, BP 1274 Antananarivo 101,

Madagascar

Full list of author information is available at the end of the article
} 


\section{Background}

In Madagascar, an intensive campaign to eliminate malaria begun in 1949 by applying indoor residual spraying (IRS) with DDT insecticide [1]. This vector control activity was intensified during the Global Malaria Eradication Campaign between 1955 and 1970 [2]. Implemented successfully throughout the entire country, in association with chloroquine treatment for malaria patients at a community level [3], these interventions led to a significant decrease in the number of confirmed cases [4]. DDT was sprayed on the interior and exterior walls of houses in a general campaign that was named 'Operation de Pulvérisation Intradomiciliaire d'Insecticides' (OPID). A temporary elimination of malaria was noted at the beginning of the 1970s. During the same period, Anopheles funestus, the primary malaria vector disappeared from the Central Highlands area, except in three districts [5]. The abandonment of OPID in 1979, the discontent with health structures and the re-invasion of the Central Highlands by $A n$. funestus led to a malaria outbreak in 1986 [4,6,7]. In response, a vector control programme was implemented from 1993 to 1998. Here DDT was used for IRS in the Central Highlands at altitudes between 1,000 and 1,500 m that delimit the area prone to malaria epidemics. This campaign was locally known as 'Campagne d'Aspersion Intradomiciliaire d'Insecticide' (CAID) [8]. In parallel, treatment with chloroquine was incorporated in areas where a high risk of malaria outbreaks was detected [9]. From 1999 until 2005 CAID were replaced by more selective operations in restricted areas above $900 \mathrm{~m}$. The Malagasy National Malaria Control Programme revised its strategy and pyrethroid insecticides replaced DDT in 2005 for IRS in the highlands.

At the end of the 1960s all DDT use was banned in the majority of developed countries but exceptions were made for countries needing essential public health interventions. However, its low cost and persistence make DDT a very useful insecticide and it is thus still used for IRS in resource-poor countries. DDT is not easily biodegradable and there is evidence of adverse effects to human health, so it was widely agreed that a replacement insecticide with the same cost-effectiveness has to be found [10-12]. Madagascar, like other countries with unstable and epidemic-prone areas was authorized to use DDT for disease vector control until the availability of an equally effective alternative insecticide [13]. The pyrethroid class of insecticides was derived from the natural pyrethrum pesticide produced by Chrysanthemum flowers. Produced by the chemical industry, pyrethroids are described as an alternative to DDT for IRS and the only insecticides recommended by the WHO for impregnating bed nets $[14,15]$.

The emergence of resistance of several malaria vectors to insecticides threatens successful malaria vector control in some countries [16]. New tools were suggested for reducing malaria transmission, but nevertheless, chemical insecticides are still essential $[17,18]$, and in most malariaendemic countries, especially sub-Saharan Africa, IRS remains an important method of fighting endophilic malaria vectors $[19,20]$.

This article compiles results dispersed in grey literature of the Institut Pasteur de Madagascar [21-23]. It reports the effectiveness of four regimens of IRS for malaria vector control in the Malagasy Central Highlands: absence of IRS, IRS with DDT or alternatively with two pyrethroids (deltamethrin and alphacypermethrin). The strengths and weaknesses of IRS and the need for complementary tools for effective malaria vector control are discussed.

\section{Methods}

\section{Study area}

The study area is located in the district of Tsiroanomandidy in the western foothills of the Malagasy Central Highlands, more precisely in the western and right bank of the Sakay River (Figure 1). The entomological study was conducted in three communes, Andranonahoatra (ANH) (1900’34"S; 46²5'21"E; 920 m a.s.l.), Soanierana (SOA) (19 $\left.08^{\prime} 42^{\prime \prime} \mathrm{S} ; 4^{\circ} 25^{\prime} 26^{\prime \prime} \mathrm{E} ; 900 \mathrm{~m}\right)$, and Analamiranga (AMG) $\left(19^{\circ} 14^{\prime} 35^{\prime \prime} \mathrm{S} ; 46^{\circ} 16^{\prime} 22^{\prime \prime} \mathrm{E} ; 885 \mathrm{~m}\right)$. In strait line, the distances ANH-SOA and SOA-AMG are 14 and $16 \mathrm{~km}$, respectively. The Mahasolo meteorological station, about in the middle of the study area, recorded annual rainfalls of 2,022 and 2,142 $\mathrm{mm}$ in 2003 and 2004, respectively, and 105 rainy days for each year. Minimal and maximal mean temperatures were $12.0^{\circ} \mathrm{C}$ and $32.0^{\circ} \mathrm{C}$ for the whole study (Figure 2). The villages ANH, SOA and AMG have 1,002, 1,274 and 900 inhabitants, respectively. Most are farmers with rice as their main activity/resource and maize, manioc and peanuts as their secondary crop. They declared not to sleep under a mosquito net, except one couple in SOA and three couples in AMG. Zebus in the three villages were 400, 160 and 390, respectively; they stay at night in parks located inside villages. The houses were built by mud with thatched or iron sheet roofing and with or without flooring.

The parasitological study was conducted in schools of the communes Ankadinondry-Sakay, Mahasolo and Maroharona, in which are located the villages ANH, SOA and AMG, respectively. As most of surrounding areas, the communes Ankadinondry-Sakay and Mahasolo were DDT sprayed annually in the nineteen's, but not in 2002 . The commune Maroharona was not sprayed at all during the three decades previous to the present survey [24].

In this area, like in the western part of the Malagasy highlands at similar altitudes, malaria is endemic. The transmission is performed by one major vector, $A n$. funestus, and two secondary vectors, Anopheles arabiensis and Anopheles mascarensis, at the exclusion of any 


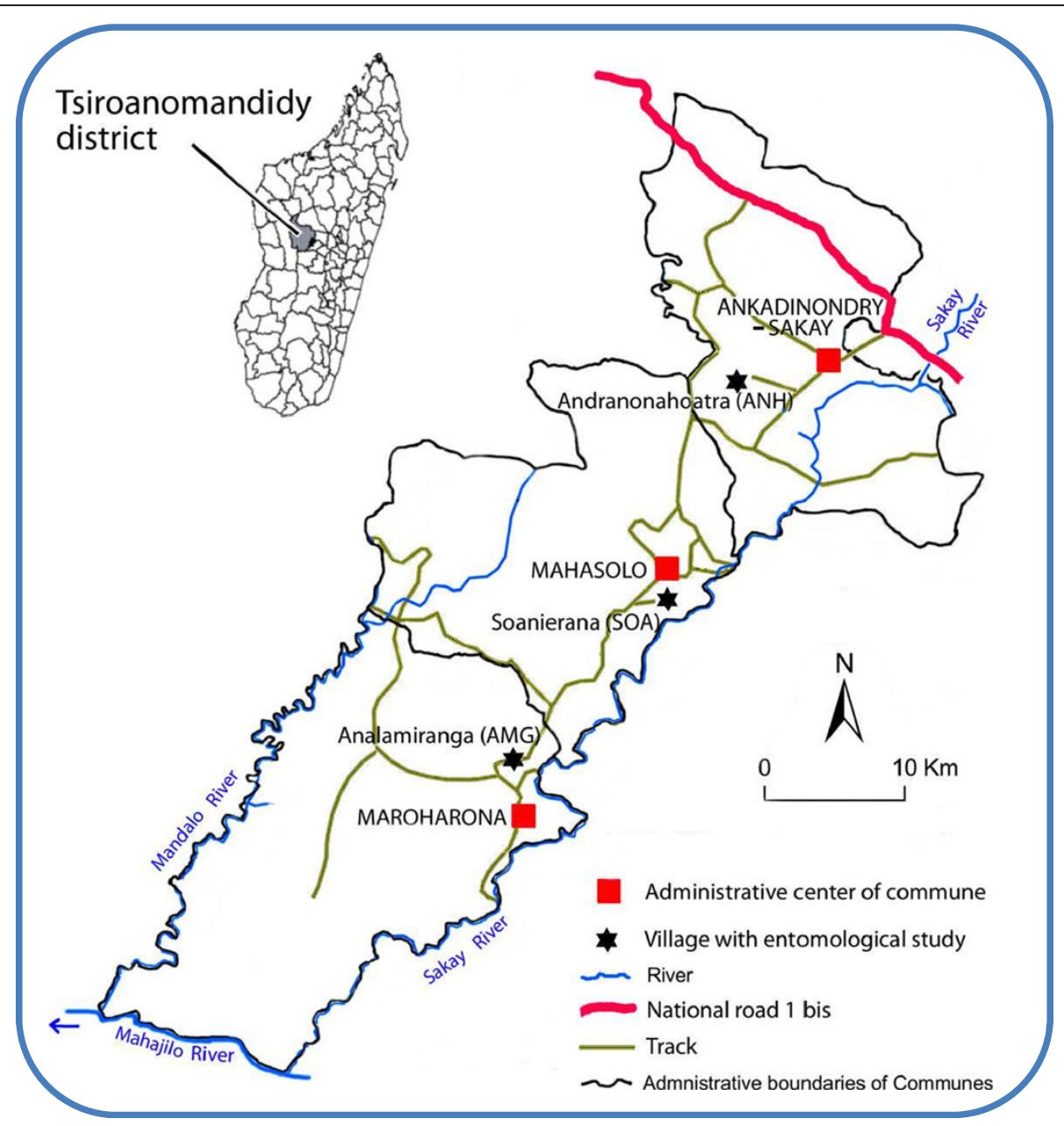

Figure 1 The study area in Madagascar.

other species [25-28]. As in most of Madagascar, these anophelines exhibit a strong tendency to exophily, both for biting and resting behaviour, and zoophily for bloodmeals [24,29]. The zoophily of An. funestus greatly contrasts with the whole of tropical Africa where this species is mainly anthropophilic [30]. It has been suggested that DDT house-spraying campaigns performed in the Malagasy highlands might had selected for behavioural change on a genetic background including zoophily in the behavioural repertoire [31]. The prevalence of

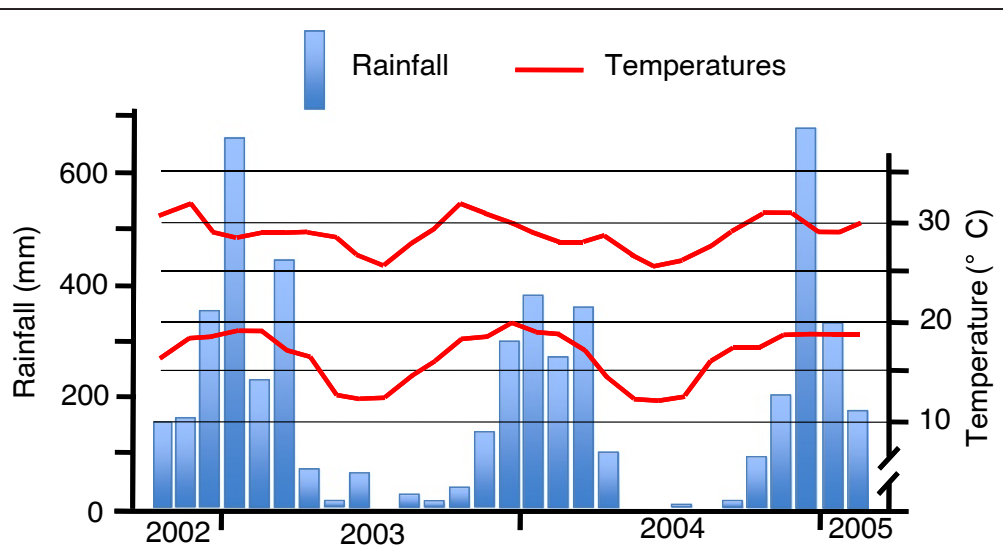

Figure 2 Minimal and maximal mean temperatures and rainfall recorded at Mahasolo, from October 2002 to February 2005. 
blood parasite in children is known to greatly vary between near zero and 50\%, depending of various parameters such as the season, the existence of IRS, and the access to anti-malarial drugs and health facilities [24,32-34].

\section{Study design}

In the two communes of Ankadinondry-Sakay and Mahasolo the study was conducted with three sequences of activities (pre-treatment, IRS with DDT and IRS with pyrethroids). The commune Maroharona remained untreated. Entomological observations were repeated monthly and parasitological surveys every three-month period (Figure 3). The study was carried out during 29 months from October 2002 to February 2005. The Malagasy Health and Education Authorities approved the entire protocol.

\section{Insecticide spraying}

IRS was carried out in a routine way by the Malagasy National Malaria Control Programme team with community participation and agreement. Three insecticides were used: $75 \%$ pure DDT wettable powder sprayed at $2 \mathrm{~g}$ of active ingredient (a.i.)/sq $\mathrm{m}$, an alphacypermethrin (pyrethroid) wettable powder (Fendona ${ }^{\circ}$ ) sprayed at $30 \mathrm{mg}$ a.i./sq $\mathrm{m}$ and a deltamethrin (pyrethroid) WG 250 wettable powder (K-Othrine $\mathrm{WG}_{250^{\circ}}$ ) sprayed at $25 \mathrm{mg}$ a.i./sq $\mathrm{m}$. The insecticides used were approved by WHO. A first round of IRS was carried out with DDT at the end of February 2003 in the two communes Ankadinondry-Sakay and Mahasolo and a second round at the end of February 2004 with deltamethrin in the commune Mahasolo and with alphacypermethrin in the commune Ankadinondry-Sakay.

\section{Entomological investigations}

Entomological study was performed routinely, once a month during the whole study, in the three villages $\mathrm{ANH}, \mathrm{SOA}$ and AMG, except in SOA during the five months May to September 2003 and in the three villages in October 2004 (Figure 3).

\section{Human landing catch}

Monthly mosquito collections were carried out from 06.00 p.m. to 06.00 a.m. when landing on human beings inside and outside houses, according to WHO procedures [35]. Two consecutive nights of mosquito collections were carried out per village and per month, in four houses, with four mosquito collectors (two inside and two outside houses) per night. Consequently, a total of 16 human-nights were performed per month in each village and the total of human-nights was 1,384 for the whole study.

\section{Collection of resting mosquito}

Resting mosquitoes were collected indoors and outdoors. Endophilic resting mosquitoes were collected mornings from 10 bedrooms per village and per month. The technique involved spraying a non-permanent insecticide (with aerosols containing pyrethroids) in a room where all exits were blocked as effectively as possible. Mosquitoes killed or simply stunned by the effect of insecticide fell on white sheets placed on the floor or furniture. All mosquitoes at rest in the room were collected. The total of bedroom-nights was 660 for the whole study. Exophilic resting mosquitoes were collected early after sunrise in two to five (mean 3.7 for the whole study) Muirhead-Thomson's pit shelters per village [36] and in various resting places such as animal shelters and cart sheds. Any exophilic mosquitoes that were found

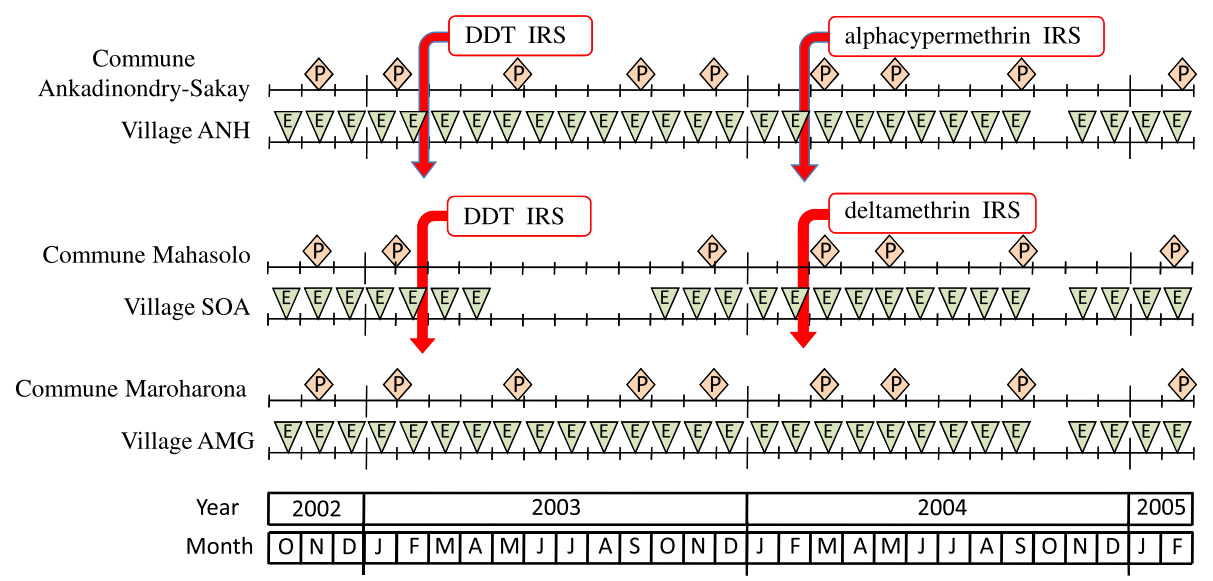

Figure 3 Chronogram of studies performed in Ankadinondry-Sakay commune, including the village Andranonahoatra (ANH), Mahasolo commune, including the village Soanierana (SOA), and Maroharona commune, including the village Analamiranga (AMG). The parasitological and entomological surveys are noted ' $P$ ' and 'E', respectively. Indoor residual spray (IRS) with DDT and pyrethroids were performed in February 2003 and February 2004, respectively; the Maroharona commune remained untreated. 
were drawn up with a sucking tube. A total of 166 pitnights and a non-registered number of other resting places were visited during the whole study.

\section{Mosquito identification}

The mosquitoes were morphologically identified using taxonomic keys [25,30]. Legs or wings of mosquitoes from the An. gambiae complex were used for PCR identification [37]. Extracted DNA from these mosquito parts was added to the reaction mixture. The amplification was done under the following conditions: $5 \mathrm{~min}$ at $94^{\circ} \mathrm{C}$ followed by $30 \mathrm{cy}-$ cles of $1 \mathrm{~min}$ at $94^{\circ} \mathrm{C}, 50 \mathrm{sec}$ at $50^{\circ} \mathrm{C}$ and $50 \mathrm{sec}$ at $72^{\circ} \mathrm{C}$, with a final elongation step during $5 \mathrm{~min}$ at $72^{\circ} \mathrm{C}$. The expected sizes of the fragments were 315, 390 and 464 base pairs for An. arabiensis, An. gambiae and An. merus, respectively. These three species were previously recorded in Madagascar [38]. Anopheles funestus, An. arabiensis and An. mascarensis females were examined for parity, anthropophily and infectivity.

\section{Ovary dissection}

Ovaries from malaria vector specimens caught on human landing were dissected to determine parity rate, a proxy of the longevity, by the observation of the degree of ovarian tracheole coiling, based on microscopic observation immediately after collection [39].

\section{Blood feeding patterns of resting mosquito}

Engorged resting anopheline females were soon dissected and their abdomens were squashed on filter paper then dried with silica gel in the field then conserved at $4^{\circ} \mathrm{C}$ in laboratory. Blood spots were tested with ELISA with antibodies for human, bovid, pig and dog according to [40]. The absorbance was recorded at $405 \mathrm{~nm}$ and $620 \mathrm{~nm}$ with an ELISA plate reader (Biotek EL 800).

\section{Estimation of the mosquito infection}

Head and thorax were dissected and processed by ELISA in a first step, using monoclonal antibodies against Plasmodium circumsporozoite protein (CSP) and, if positive, in a second step, monoclonal antibodies against Plasmodium falciparum, $P$. malariae, $P$. vivax 210 or $P$. vivax 247 in order to determine the Plasmodium species $[41,42]$. Results on P. malariae were not presented, obviously spoiled by numerous false positives (see discussion). ELISA was not performed using antibodies against P. ovale.

\section{Entomological indicators}

The daily biting rate, an estimation of man-mosquito contact, was calculated as the ratio of the number of mosquitoes caught landing on human subjects to the number of human-nights. The endophagic rate was estimated from mosquitoes sampled by human landing collection indoor / (indoor + outdoor). The anthropophilic rate was calculated as the number of mosquitoes fed on human beings divided by the number the gorged mosquitoes tested for blood meal analysis; following [43-45], mixed human blood meals were included in this calculation, but mosquitoes with unidentified blood meal sources were excluded. The parity rate was the ratio of the number of parous females to the number of parous + nulliparous females; it was calculated using the biting females [46]. The infectivity rate was the ratio of the number of mosquitoes positive by ELISA for $P$. falciparum $+P$. vivax to the number of examined mosquitoes. The entomological inoculation rate (EIR) was the product of the biting rate and infectivity rate. This calculation was performed daily taking the anopheline vector species one by one, then summed in the final step. Since dwellers spend all nights in their houses, the human biting rate was considered indoors for EIR calculation.

\section{Parasitological and clinical investigations}

Parasitological surveys were performed about every three months from November 2002 to February 2005, in the schools of the two communes Mahasolo and Ankadinondry-Sakay, except during the months May to September 2003 in Ankadinondry-Sakay (Figure 2). Informed consent for the participation of the schoolchildren was obtained from their legal guardians. Every transversal survey concerned at least 400 schoolchildren present at school the day of the survey in the primary schools of the commune Ankadinondry-Sakay (Ecole Publique Primaire (EPP) Andranonahoatra and EPP Soamihary), the commune Mahasolo (EPP Soanierana, EPP Maevarano and EPP Ambohimandroso Bemasoandro) and the commune Maroharona (Sainte-Thérèse Analamiranga, EPP Analamiranga and EPP Ampasipotsy). Any child was questioned for symptoms related to malaria; if the presence of malaria was suspected, the child was treated in agreement with the national health policy.

A drop of blood was collected from the fingertip and thick and thin blood smears were prepared and giemsa stained. Thick blood film readings were standardized and quality control was performed. Parasite densities were determined by counting the number of asexual parasites per 200 white blood cells (WBCs) or per 500 WBCs if the count was less than 10 parasites/200 WBCs. Assuming a WBC count of $8,000 / \mathrm{mm}^{3}$, the sensitivity threshold was estimated at 16 parasites $/ \mathrm{mm}^{3}$. The thin smear was used if plasmodial species determination was doubtful in thick smear. The proportion of people who are infected with any Plasmodium was expressed as the plasmodial index. The total of blood smears was 5,174 for the whole study.

Fever was defined as an axillary temperature $\geq 37^{\circ} \mathrm{C}$. Malaria attack was defined as an association of fever and 
asexual parasite of Plasmodium spp. in blood smear; no minimal parasite density was assigned to define a malaria attack, in line with previous studies performed in this area [47].

\section{Data processing}

Entomological, demographic, parasitological and clinical data were entered in an Excel database (Additional file 1: Table S1 and Additional file 2: Table S2) and analysed using STATA 11.0 statistical software (StataCorp LP, College Station, TX: Stata Corporation, 2009). The base line data were provided from October 2002 to February 2003, i.e. during the period previous to any IRS.

The numbers of mosquitoes caught on humans (indoors and outdoors) and at rest (in bedrooms and in pit shelters) were analysed in population-averaged negative binomial regression models using a generalized estimating equations (GEE) approach taking into account an exchangeable within-village and survey correlation structure. The rates of endophagy, parity, anthropophily and infectivity of the mosquitoes were analysed in population-averaged logistic regression models using a GEE approach and taking into account an exchangeable within-site and survey correlation structure. The villages, the type of IRS (DDT, alphacypermethrin and deltamethrin), the periods (i.e. trimesters or years of survey) and the catching location (indoors and outdoors) were initially introduced in full regression models. The interactions between the effect of periods, the catching location and the type of IRS were tested. A backward stepwise selection procedure was applied to retain the significant $(P<0.05)$ independent variables.

Prevalence rates of plasmodial infections and clinical malaria attacks were estimated with their $95 \%$ confidence intervals (CI) taking into account the interdependence of observations made in the same site and during the same survey, and were analyzed as dependent variables in population-averaged logistic regression models using a GEE approach and taking into account an exchangeable within-commune and survey correlation structure. The communes, the type of IRS (DDT, alphacypermethrin and deltamethrin), the periods, the age and the sex were initially introduced in a full logistic regression model. A backward stepwise selection procedure was applied to retain the significant $(\mathrm{P}<0.05)$ independent variables. The statistical quality of the final models was assessed by looking at the adequacy between observed and predicted prevalences.

The differences between villages/communes, periods, type of catching and type of IRS were tested by the Wald test, and 95\% CI of adjusted odds ratio (OR) or incident relative risk (IRR) were calculated. The data processing takes into account the gap previously mentioned in the data collection due to problems in funds availability in the Mahasolo commune during the five-month period, March-September 2003 (Figure 2). The data collected during this period were excluded from the regression analysis.

\section{Results}

Mosquitoes and malaria transmission

Mosquito species composition and relative abundance

A total of 8,001 An. gambiae s.l. was collected with various methods during the whole study. A sample of 2,287 was PCR identified and unambiguously assigned to a single species, An. arabiensis. In human landing catches, 18,168 mosquitoes were collected (Table 1). Anopheles was the most abundant mosquito genus collected with 13,427 (73.9\%) as against 3,979 Culex (21.9\%), 676 Mansonia (3.7\%), 76 Aedes (0.4\%) and 10 Coquilletidia (0.1\%). Three species of potential malaria vectors, $A n$. funestus, An. arabiensis and An. mascarensis, accounted for $30.0 \%$ of the mosquitoes and $40.6 \%$ of anophelines. Using the methods for collection of resting mosquitoes, 12,932 of these three anopheline species were collected (Table 2). After IRS, no change was noted in species composition of mosquitoes in the different villages.

\section{Biting rate}

The evolution of daily biting rate of An. funestus, $A n$. arabiensis and An. mascarensis is presented Figures 4, 5 and 6. Overall, these species accounted for $72.3 \%, 21.2 \%$ and $6.5 \%$ of malaria vectors biting indoors and 50.7\%, $24.2 \%$ and $25.1 \%$ of malaria vectors biting outdoors, respectively.

During the first, third and fourth trimesters post-DDT IRS, compared to the pre-IRS period and controlling for the variation of the anopheline aggressiveness in Analamiranga, the biting rate for the sum of the three malaria vectors was $83 \%$ to $94 \%$ (depending of trimester) lower in Andranonahoatra $(0.06<\mathrm{IRR}<0.17,0.44<\mathrm{P}<0.0001)$, suggesting an impact of IRS with DDT. Similar observations were done during the first and second trimesters post-pyrethroid IRS in both Soanierana and Andranonahoatra $(0.16<\mathrm{IRR}<0.05,0.008<\mathrm{P}<0.0001)$ suggesting an impact of IRS with pyrethroids. This reduction was also observed in the third trimester postpyrethroid but without significant difference.

Considering An. funestus alone, and considering successively each of the four trimesters post-pyrethroid IRS, compared to the pre-IRS period and controlling for the variation of the aggressiveness in Analamiranga, no significant difference was observed between the two sprayed villages, suggesting a similar impact (1) of DDT in each of the two sprayed villages, and (2) of alphacypermethrin and deltamethrin. Considering An. arabiensis alone, similar observations were done in trimesters 1 , 3 and 4 post-pyrethroid IRS. This was not observed in trimester 2, with significant lower IRR in Soanierana than in Andranonahoatra (IRR=0.08 and $I R R=13.0$, 
Table 1 Number of mosquitoes collected by human landing catch indoors and outdoors

\begin{tabular}{|c|c|c|c|c|c|c|c|}
\hline \multirow[t]{2}{*}{ Village } & \multicolumn{2}{|c|}{ Andranonahoatra } & \multicolumn{2}{|c|}{ Soanierana } & \multicolumn{2}{|c|}{ Analamiranga } & \multirow[t]{2}{*}{ Total } \\
\hline & Indoors & Outdoors & Indoors & Outdoors & Indoors & Outdoors & \\
\hline An. coustani & 103 & 308 & 451 & 1,901 & 100 & 991 & 3,854 \\
\hline An. funestus & 72 & 132 & 69 & 151 & 1,035 & 2,374 & 3,833 \\
\hline An. squamosus-cydippis & 25 & 109 & 364 & 1,475 & 27 & 191 & 2,191 \\
\hline An. arabiensis & 98 & 260 & 200 & 758 & 47 & 251 & 1,614 \\
\hline An. mascarensis & 18 & 108 & 26 & 185 & 61 & 1,022 & 1,420 \\
\hline An. maculipalpis & 8 & 56 & 23 & 140 & 10 & 131 & 368 \\
\hline An. rufipes & 2 & 10 & 9 & 20 & 3 & 29 & 73 \\
\hline An. pharoensis & 1 & 5 & 5 & 16 & 0 & 4 & 31 \\
\hline An. flavicosta & 1 & 0 & 1 & 3 & 3 & 19 & 27 \\
\hline An. pretoriensis & 0 & 4 & 0 & 0 & 3 & 9 & 16 \\
\hline Culex spp. & 139 & 506 & 422 & 1,678 & 274 & 960 & 3,979 \\
\hline Mansonia uniformis & 26 & 90 & 61 & 234 & 50 & 215 & 676 \\
\hline Aedes spp. & 0 & 4 & 4 & 32 & 8 & 28 & 76 \\
\hline Coquillettidia grandidieri & 1 & 6 & 0 & 2 & 1 & 0 & 10 \\
\hline Total (\%) & $494(2.7)$ & 1,598 (8.8) & $1,635(9.0)$ & $6,595(36.3)$ & 1,622 (8.9) & $6,224(34.3)$ & $18,168(100.0)$ \\
\hline
\end{tabular}

respectively, Chi square $=8.11, \mathrm{df}=1, \mathrm{P}=0.0044$ ), but this is probably due to the quasi absence of $A n$. arabiensis during this trimester in Analamiranga (Figure 5). The biting rate of $A n$. mascarensis indoors was very low (daily mean $=0.13$ ) and its variation was not statistically analysed.

The aggressiveness outdoors was consistently higher than indoors. During the whole study, the endophagic rate for biting activity was $30.5 \%, 21.3 \%$ and $8.0 \%$ for $A n$. funestus, An. arabiensis and An. mascarensis, respectively. Overall, the risk for being bitted by anopheline vectors was much higher outdoors than indoors (IRR = 3.78, $\mathrm{P}<0.0001)$.

\section{Density of indoor- and outdoor-resting anophelines}

The three malaria vectors An. funestus, An. arabiensis and $A n$. mascarensis represented $49.4 \%, 45.4 \%$ and $5.2 \%$ of resting anophelines (Table 2). The number of bedrooms used for pyrethrum spray catches was 280, 230 and 280 in Andranonahoatra, Soanierana and Analamiranga, respectively; therefore the density per room of resting vectors was $1.77,0.91$ and 6.29 , respectively, suggesting a strong impact of IRS in lowering the densities indoors. Such difference was not observed in vectors resting outdoors, an observation that can be related to the fact that insecticide was exclusively sprayed indoors.

\section{Blood meal identification}

Among the mosquitoes collected at rest, a total of 4,514 gorged anophelines was tested for blood feeding patterns during the whole study, and the blood source was identified for 4,396 (97.4\%). The blood of human, bovid, pig and dog was present in $14.2 \%, 85.1 \%, 1.6 \%$ and $1.7 \%$, respectively (total $=103.7 \%$ due to 118 mixed blood meals).

The anthropophilic rate (AR) was $28.8 \%, 2.5 \%$ and $1.6 \%$ in An. funestus, An. arabiensis and An. mascarensis, respectively. AR was consistently higher in mosquitoes resting indoor in bedrooms than resting outdoor (Table 3), in line with the usual habit for human beings to sleep inside house and conversely for zebus to spend the night outdoors in enclosures within the village perimeter. The incident relative risk (IRR) for a blood meal of An. funestus to be taken on human being was 0.06 outdoors compared to 1 indoors $(\mathrm{P}<0.0001)$, whatever the period, before or after any IRS.

Table 2 Number of resting anophelines and percentage of catch per village and resting location

\begin{tabular}{|c|c|c|c|c|c|c|c|}
\hline \multirow[t]{2}{*}{ Village } & \multicolumn{2}{|c|}{ Andranonahoatra } & \multicolumn{2}{|c|}{ Soanierana } & \multicolumn{2}{|c|}{ Analamiranga } & \multirow[t]{2}{*}{ Total (\%) } \\
\hline & Bedroom resting & Outdoor resting & Bedroom resting & Outdoor resting & Bedroom resting & Outdoor resting & \\
\hline An. funestus & 355 & 2,537 & 58 & 2,459 & 49 & 930 & $6,388(49.4)$ \\
\hline An. arabiensis & 134 & 939 & 151 & 582 & 1,700 & 2,360 & $5,866(45.4)$ \\
\hline An. mascarensis & 6 & 200 & 1 & 124 & 12 & 335 & $678(5.2)$ \\
\hline Total (\%) & 495 (3.8) & $3,676(28.4)$ & $210(1.6)$ & $3165(24.5)$ & $1,761(13.6)$ & $3,625(28.0)$ & $12,932(100.0)$ \\
\hline
\end{tabular}



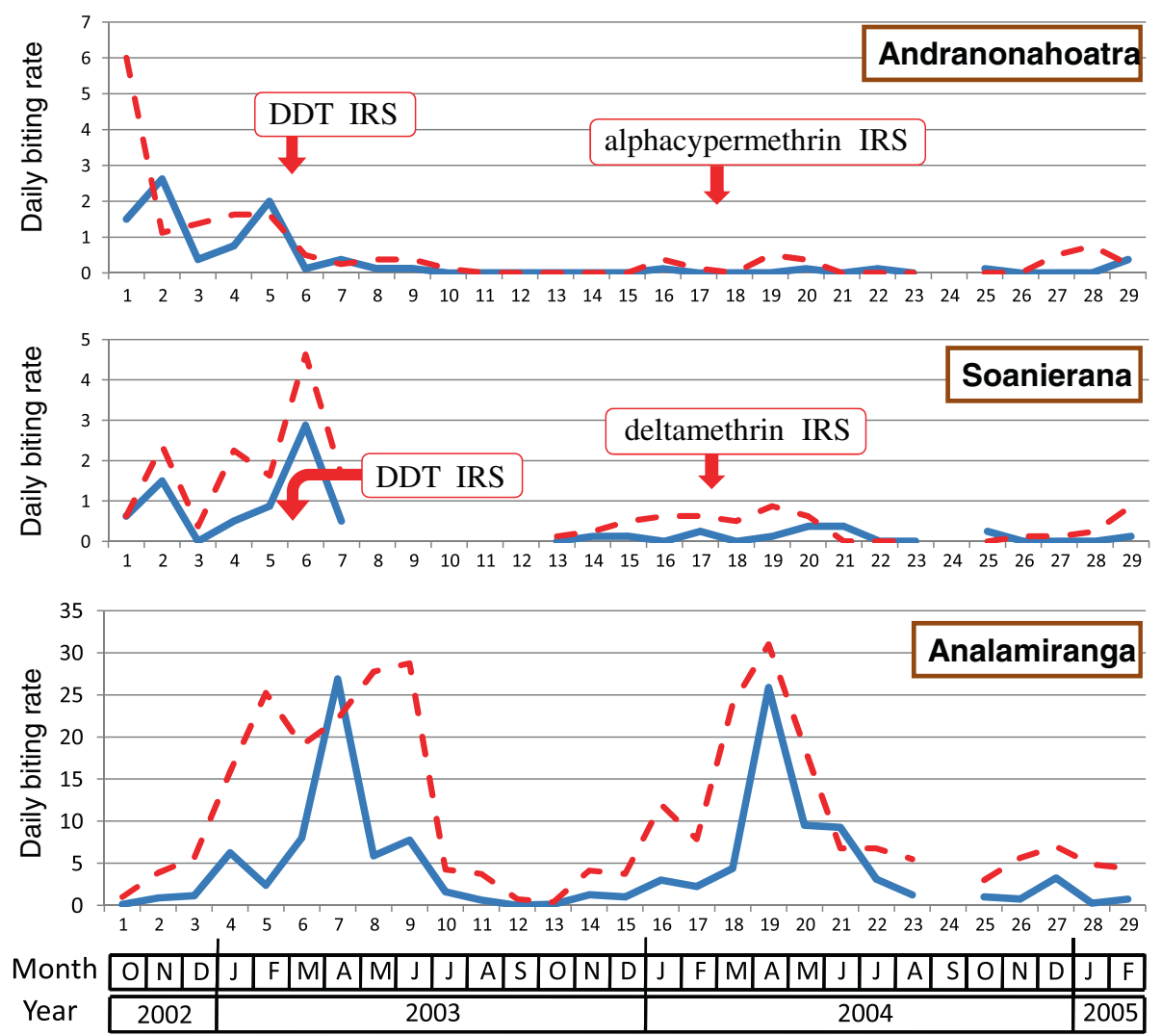

Figure 4 Daily biting rate of An. funestus (number of bites per human and per night) in the villages of Andranonahoatra, Soanierana and Analamiranga. Mosquitoes were collected by human landing indoors (blue line) and outdoors (red dashed line). Indoor residual spray (IRS) with DDT and pyrethroids were performed in February 2003 and February 2004, respectively; the Maroharona commune remained untreated.

During the whole study, the mean AR of An. funestus was lower in Andranonahoatra and Soanierana, compared to Analamiranga (27\%, $27 \%$ and $48 \%$, respectively) (Table 4). Considering the AR of An. funestus during the pre-IRS period, the differences were statistically significant between villages $(\mathrm{OR}=0.31, \mathrm{P}<0.001$ for Andranonahoatra; $\mathrm{OR}=0.44, \mathrm{P}=0.024$ for Soanierana, compared to $\mathrm{OR}=1$ for Analamiranga). A significant higher AR of An. funestus was observed during the IRS period with DDT compared to the pre-IRS period $(\mathrm{OR}=7.72, \mathrm{P}<0.001)$. This unexpected result was mainly due to mosquitoes collected indoors in March 2003 in Soanierana. No significant variation in AR of An. funestus was observed during the IRS period with pyrethroids compared to the pre-IRS period. These results suggest that IRS did not reduce the AR of An. funestus collected at rest. Such analysis failed to test the impact of IRS on ARs of An. arabiensis and An. mascarensis due to their very low ARs, especially in Analamiranga, and the impossibility to adjust the models because of the absence of detection of blood meals on humans during the baseline period in some villages.

\section{Parous rate}

The mean parous rate (PR) of An. funestus, An. arabiensis and An. mascarensis was $88.6 \%, 64.9 \%$ and $87.1 \%$, respectively. In the untreated village of Analamiranga, the PR of the three vectors was similar in human landing catches indoors and outdoors, like in resting sites indoors and outdoors (Table 5).

The mean parous rate of An. funestus was $85.6 \%$, $86.0 \%$ and $89.4 \%$ in Andranonahoatra, Soanierana and Analamiranga, respectively (Table 6). These differences were not statistically significant. No significant differences were observed in PR of An. funestus collected (1) in Andranonahoatra and Soanierana compared to Analamiranga during the pre-IRS period and (2) outdoors compared to indoors during the whole study. Compared to pre-IRS period, a significant impact of IRS with DDT was observed in reducing the $P R(O R=0.47, P=0.001)$, but without significant reduction of IRS with pyrethroid $(\mathrm{OR}=0.98)$. Such analysis failed to test the impact of IRS on PRs of An. arabiensis and An. mascarensis due to their very low PRs and the impossibility to adjust the models. 

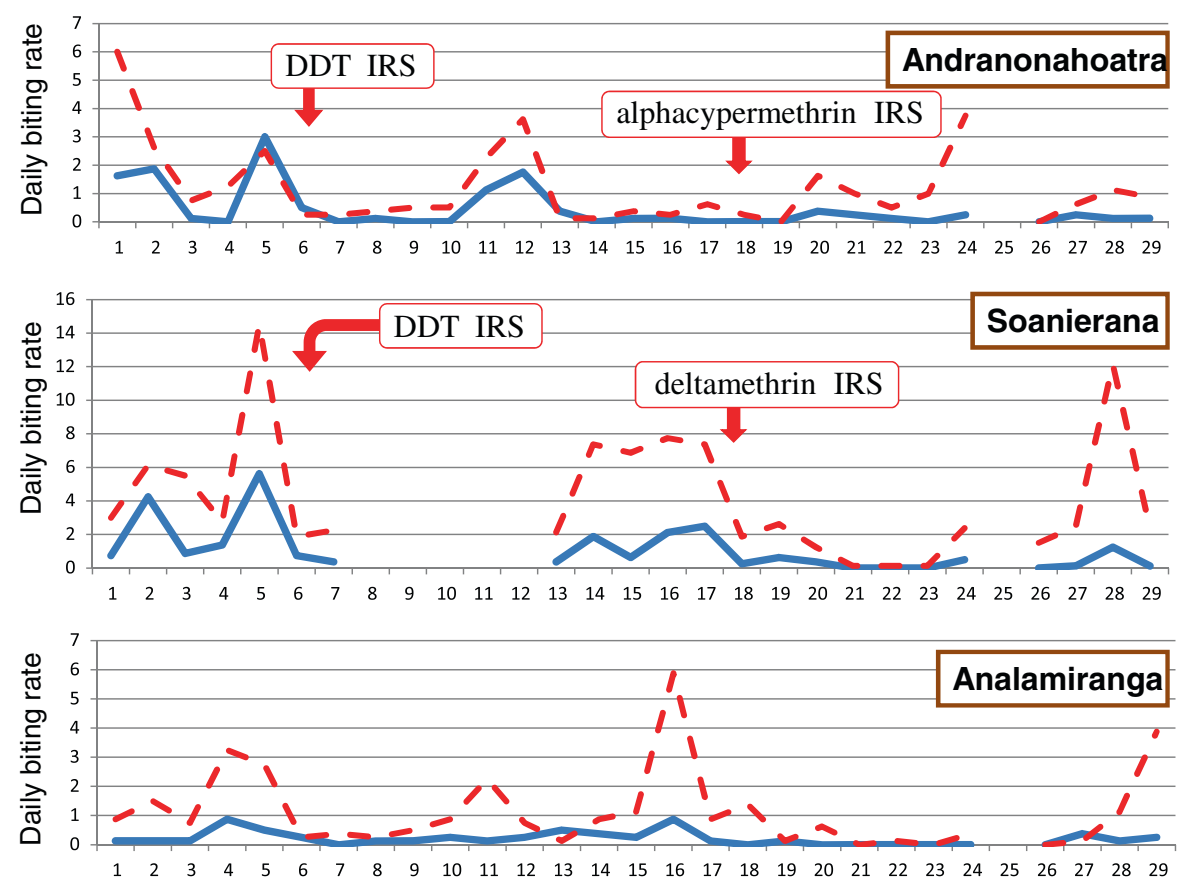

\begin{tabular}{|c|c|c|c|c|c|c|}
\hline & \begin{tabular}{|l|l|l|}
$\mathrm{O}$ & $\mathrm{N}$ & $\mathrm{D}$ \\
\end{tabular} & \begin{tabular}{|l|l|l|l|l|}
$\mathrm{J}$ & $\mathrm{F}$ & $\mathrm{M}$ & $\mathrm{A}$ & $\mathrm{M}$ \\
\end{tabular} & \begin{tabular}{|l|l|l|l|l|l|l|l|l|}
$\mathrm{J}$ & $\mathrm{J}$ & $\mathrm{A}$ & $\mathrm{S}$ & $\mathrm{O}$ & $\mathrm{N}$ & $\mathrm{D}$ \\
\end{tabular} & \begin{tabular}{|l|l|l|l|l|l|l} 
& $J$ & $F$ & $M$ & $A$ & $M$ & $J$ \\
\end{tabular} & \begin{tabular}{|l|l|l|l|l|l|l|}
$\mathrm{J}$ & $\mathrm{J}$ & $\mathrm{A}$ & $\mathrm{S}$ & $\mathrm{O}$ & $\mathrm{N}$ & $\mathrm{D}$ \\
\end{tabular} & 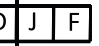 \\
\hline & 2002 & & 2003 & & 2004 & 2005 \\
\hline
\end{tabular}

Figure 5 Daily biting rate of An. arabiensis (number of bites per human and per night) in the villages of Andranonahoatra, Soanierana and Analamiranga. Mosquitoes were collected by human landing indoors (blue line) and outdoors (red dashed line). Indoor residual spray (IRS) with DDT and pyrethroids were performed in February 2003 and February 2004, respectively; the Maroharona commune remained untreated.

\section{Mosquito infection}

A total of 20 anophelines were ELISA-CSP positive with, 15, 3 and 2 An. funestus, An. arabiensis and An. mascarensis, respectively (Table 7 ). The three species are readily involved in the Plasmodium transmission in the three villages, except An. mascarensis in Andranonahoatra. The temporal distribution of these mosquitoes is presented Figure 7. They were obtained using human landing catches (two indoors and eight outdoors), and collection of mosquitoes at rest in bedrooms (6) and in exophilic places (three in pit shelters and one in a hole). The parasite species $P$. falciparum and $P$. vivax were recorded in 12 and 8 anophelines, respectively (Table 7). In the AMG village that remained IRS untreated for the whole study, the mean sporozoitic index (SI) was $0.17 \%$, $0.08 \%$ and $0.07 \%$ in An. funestus, An. arabiensis and $A n$. mascarensis, respectively (Table 8 ). The mean SI for the three vectors was not significantly different between villages during the pre-IRS period, after IRS with DDT and after IRS with pyrethroids.

\section{Entomological inoculation rate (EIR)}

The daily EIR values per village and period underlined (1) the major contribution of An. funestus in the EIR, (2) the differences between villages during the pre-treatment period, and (3) the impact of IRS with pyrethroid (Table 9). Faced to the small sample of infected anophelines and to the difficulty of managing the individual variability of the biting rate, the statistical analysis of the EIR was not attempted.

\section{Schoolchildren and blood parasites}

The 5,174 blood smears were obtained from schoolchildren ranging 4 to 16 years old (99.3\% between 6 and 12), with a sex ratio $(\mathrm{M} / \mathrm{F})$ of 0.856 , and a mean axillary temperature of $37.0^{\circ} \mathrm{C}$ (maximum 41.4). Overall, 1,030 blood smears (19.9\%) presented at least one parasite belonging to the genus Plasmodium. The four Plasmodium species infecting humans were encountered in the following proportion: $P$. falciparum $89.6 \%, P$. vivax $12.5 \%$, P. malariae $1.3 \%$ and $P$. ovale $0.5 \%$ (total $=103.9 \%$ due to mixed infections). Among the 1,030 schoolchildren with blood parasites, fever was present in $512(49.7 \%)$. The mean temperature was $36.93^{\circ} \mathrm{C}$ in children without parasites versus $37.45^{\circ} \mathrm{C}$ in children with parasites. Children with both blood parasites and fever represented $9.9 \%$ of those present at school.

\section{Plasmodic index}

For the whole study, the mean plasmodic index was 10.9\%, 9.5\% and 36.9\% in Ankadinondry-Sakay, Mahasolo 

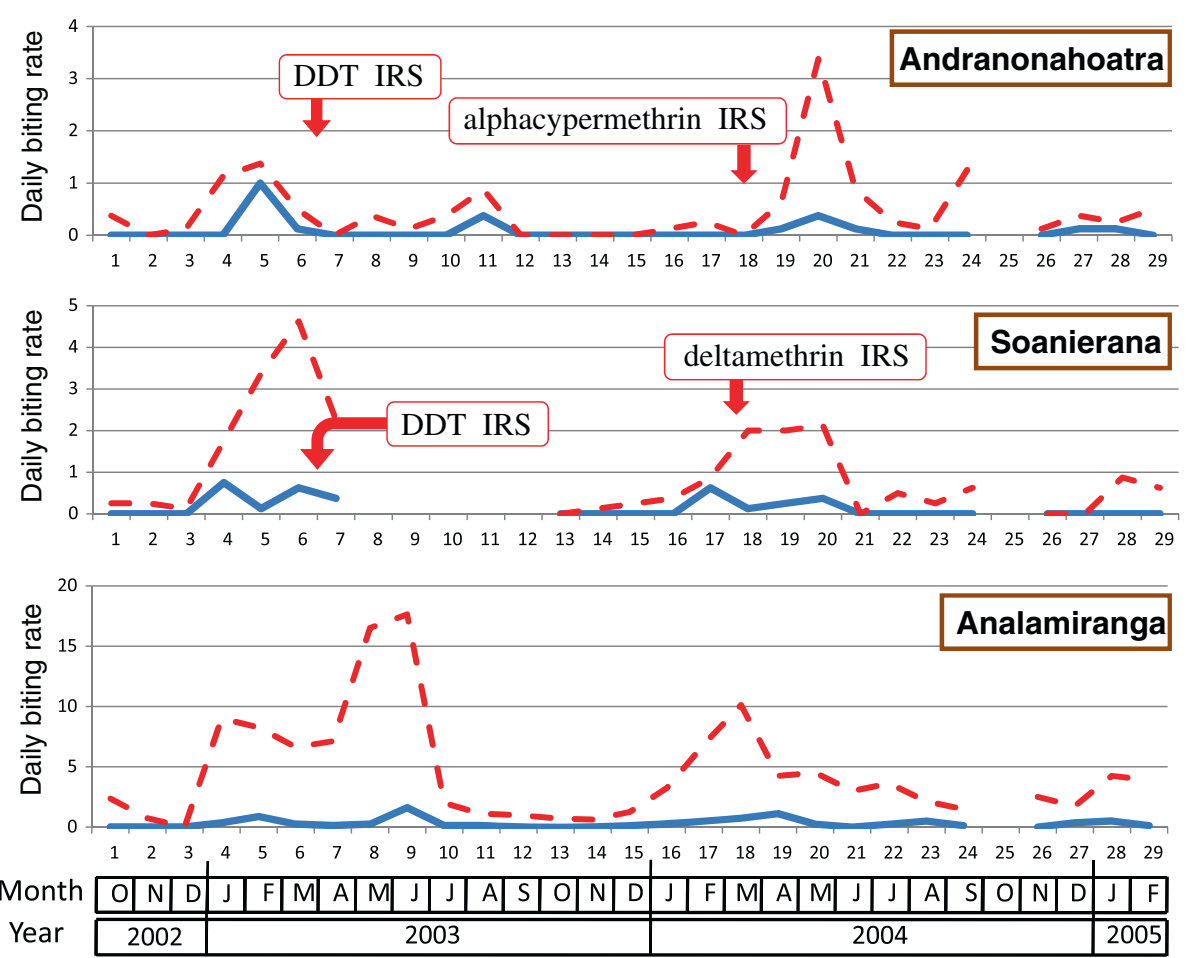

Figure 6 Daily biting rate of An. mascarensis (number of bites per human and per night) in the villages of Andranonahoatra, Soanierana and Analamiranga. Mosquitoes were collected by human landing indoors (blue line) and outdoors (red dashed line). Indoor residual spray (IRS) with DDT and pyrethroids were performed in February 2003 and February 2004, respectively; the Maroharona commune remained untreated.

and Maroharona communes, respectively (Table 10), with important seasonal variations (Figure 8).

During the pre-IRS period, this index was $13.1 \%$, $15.5 \%$ and $24.6 \%$, respectively. During this period and compared to the Maroharona commune without IRS, the plasmodic index was $57 \%$ and $40 \%$ lower in Ankadinondry-Sakay and Mahasolo, respectively (odds ratio $(\mathrm{OR})=0.43, \mathrm{P}<0.0001$ and $\mathrm{OR}=0.60, \mathrm{P}=0.002$ ), and did not differ significantly between AnkadinondrySakay and Mahasolo. In November 2003, compared to the pre-IRS period and controlling for the variation of the plasmodic index in Maroharona, the plasmodic index was $73 \%$ and $54 \%$ lower in Ankadinondry-Sakay and Mahasolo, respectively $(\mathrm{OR}=0.23, \mathrm{P}<0.0001$ and
$\mathrm{OR}=0.44, \mathrm{P}=0.012$ ), without significant difference between the two communes, suggesting an impact of IRS with DDT. After IRS with pyrethroids, compared to the pre-IRS period and controlling for the variation of the plasmodic index in the commune without IRS, the reduction of the plasmodic index varied between one month and 12 months after the IRS from $66 \%$ to $92 \%$ in the commune treated by deltamethrin (OR between 0.34 and 0.08 , always with $\mathrm{P} \leq 0.001$ ) and from $51 \%$ to $82 \%$ in the commune treated by alphacypermethrin (OR between 0.49 and 0.18 , always with $\mathrm{P} \leq 0.025)$, This reduction was significantly lower in Ankadinondry-Sakay than in Mahasolo $(\mathrm{OR}=0.33$ vs. $\mathrm{OR}=0.09, \mathrm{P}=0.038$ ), only in September 2004, i.e. 7 months after IRS with pyrethroids, sugges-

Table 3 Number of resting anophelines and anthropophilic rate (percentage of mosquitoes fed on humans), per village and resting location

\begin{tabular}{|c|c|c|c|c|c|c|c|}
\hline \multirow{2}{*}{$\begin{array}{c}\text { Village } \\
\text { Resting site }\end{array}$} & \multicolumn{2}{|c|}{ Andranonahoatra } & \multicolumn{2}{|c|}{ Soanierana } & \multicolumn{2}{|c|}{ Analamiranga } & \multirow[t]{2}{*}{ Total } \\
\hline & Bedroom resting & Outdoor resting & Bedroom resting & Outdoor resting & Bedroom resting & Outdoor resting & \\
\hline An. funestus & $61(39 \%)$ & $269(10 \%)$ & $95(65 \%)$ & $192(3 \%)$ & $692(50.3 \%)$ & $655(15.0 \%)$ & $1,964(28.8 \%)$ \\
\hline An. arabiensis & $204(5 \%)$ & $850(1.7 \%)$ & $42(5 \%)$ & $605(0.7 \%)$ & $22(14 \%)$ & $402(5 \%)$ & $2,125(2.5 \%)$ \\
\hline An. mascarensis & $2 / 3^{*}$ & $83(1 \%)$ & $0 / 1^{*}$ & $64(2 \%)$ & $0 / 9^{*}$ & $147(1 \%)$ & 307 (1.6\%) \\
\hline Total (\%) & 268 & 1,202 & 138 & 861 & 723 & 1,204 & 4396 \\
\hline
\end{tabular}

${ }^{*}$ Anthropophilic rate not calculated when No. $<25$. 
Table 4 Number of Anopheles funestus and anthropophilic rate (AR), per period before and after indoor residual spraying (IRS) with DDT or pyrethroid (pyr)

\begin{tabular}{|c|c|c|c|c|c|c|}
\hline \multirow{2}{*}{$\begin{array}{l}\text { Village } \\
\text { Period }\end{array}$} & \multicolumn{2}{|c|}{ Andranonahoatra } & \multicolumn{2}{|c|}{ Soanierana } & \multicolumn{2}{|c|}{ Analamiranga } \\
\hline & No. & AR (\%) & No. & AR (\%) & No. & AR (\%) \\
\hline Oct 02-Feb 03 (pre-IRS) & 151 & 27 & 123 & 27 & 237 & 48 \\
\hline Mar 03-Feb 04 (IRS DDT) & 97 & 6 & 96 & 34 & 553 & 24 \\
\hline Mar 04-Feb 05 (IRS pyr) & 82 & 6 & 68 & 3 & 557 & 35 \\
\hline Overall & 330 & 15.7 & 287 & 23.7 & 1,347 & 33.1 \\
\hline
\end{tabular}

ting a significantly longer impact of deltamethrin than alphacypermethrin.

\section{Density of asexual P. falciparum}

The median of log-transformed densities of asexual $P$. falciparum parasites was 329, 460 and 545 per $\mathrm{mm}^{3}$ of blood in Ankadinondry-Sakay, Mahasolo and Maroharona communes, respectively (Table 11). This median density was not statistically different between communes during the pre-IRS period, as for the all study duration. Similar conclusions were obtained without log transformation of densities (results not shown).

\section{Malaria attacks}

For the whole study, the mean incidence of malaria attacks was $4.0 \%, 4.0 \%$ and $18.0 \%$ in AnkadinondrySakay, Mahasolo and Maroharona communes, respectively (Table 12), with important seasonal variations (Figure 9).

During the pre-IRS period, the mean prevalence of clinical malaria attacks was $4.0 \%, 4.0 \%$ and $18.0 \%$ in Ankadinondry-Sakay, Mahasolo and Maroharona communes, respectively. During this period and compared to the Maroharona commune without IRS, the mean prevalence of clinical malaria attacks was $64 \%$ and $49 \%$ lower in Ankadinondry-Sakay and Mahasolo, respectively $(\mathrm{OR}=0.36, \mathrm{P}<0.0001$ and $\mathrm{OR}=0.51, \mathrm{P}=0.007)$, and did not differ significantly between Ankadinondry-Sakay and Mahasolo. In November 2003, compared to the pre-IRS period and controlling for the variation of the plasmodic index in Maroharona, the reduction of the prevalence of clinical malaria attacks was $82 \%$ in Ankadinondry-Sakay $(\mathrm{OR}=0.18, \mathrm{P}=0.001)$, although this reduction was not significant in Mahasolo $(\mathrm{OR}=0.73)$. After IRS with pyrethroids, compared to the pre-IRS period and controlling for the variation of the plasmodic index in Maroharona, the reduction of the prevalence of clinical malaria attacks did not differ significantly between Ankadinondry-Sakay and Mahasolo, and varied between one month and 12 months after the IRS from $36 \%(\mathrm{OR}=0.64, \mathrm{P}=0.193)$ to $56 \%(\mathrm{OR}=0.44, \mathrm{P}=0.094)$ with maximum reductions of $54 \%(\mathrm{OR}=0.46, \mathrm{P}=0.035)$ and $67 \%(\mathrm{OR}=0.33, \mathrm{P}=0.028)$ observed three and seven months after IRS, respectively, suggesting a significant and similar impact of deltamethrin and alphacypermethrin. Similar conclusions were obtained

Table 5 Number of malaria vectors and parous rate (PR) per method of collection, by human landing catches indoors and outdoors and by aspiration of mosquitoes at rest in bedrooms and pit shelters

\begin{tabular}{|c|c|c|c|c|c|c|c|c|c|}
\hline & \multirow[t]{2}{*}{ Village } & \multicolumn{2}{|c|}{ Andranonahoatra } & \multicolumn{2}{|c|}{ Soanierana } & \multicolumn{2}{|c|}{ Analamiranga } & \multicolumn{2}{|c|}{ Total } \\
\hline & & No. & PR (\%) & No. & PR (\%) & No. & PR (\%) & No. & PR (\%) \\
\hline \multirow[t]{4}{*}{ An. funestus } & Indoors & 70 & 84.3 & 69 & 84.1 & 900 & 89.7 & 1039 & 88.9 \\
\hline & Outdoors & 130 & 86.2 & 146 & 84.9 & 1984 & 87.9 & 2260 & 87.6 \\
\hline & Bedroom & 133 & 88.0 & 149 & 85.2 & 827 & 90.6 & 1109 & 89.5 \\
\hline & Pit shelter & 178 & 80.3 & 180 & 88.3 & 487 & 93.2 & 845 & 89.5 \\
\hline \multirow[t]{4}{*}{ An. arabiensis } & Indoors & 96 & 61.5 & 193 & 45.1 & 47 & 53.2 & 336 & 50.9 \\
\hline & Outdoors & 253 & 59.3 & 727 & 38.5 & 242 & 59.5 & 1222 & 47.0 \\
\hline & Bedroom & 277 & 81.9 & 58 & 87.9 & 48 & 83.3 & 383 & 83.0 \\
\hline & Pit shelter & 544 & 73.3 & 493 & 80.9 & 447 & 80.8 & 1484 & 78.1 \\
\hline \multirow[t]{4}{*}{ An. mascarensis } & Indoors & 19 & * & 24 & * & 66 & 89.4 & 109 & 85.3 \\
\hline & Outdoors & 105 & 76.2 & 174 & 81.0 & 869 & 88.4 & 1148 & 86.1 \\
\hline & Bedroom & 5 & * & 1 & * & 12 & * & 18 & * \\
\hline & Pit shelter & 70 & 88.6 & 91 & 86.8 & 241 & 92.1 & 402 & 90.3 \\
\hline
\end{tabular}

*Parous rate not calculated when No. of nuliparous + parous mosquitoes $<25$. 
Table 6 Number of Anopheles funestus and parous rate (PR), per trimester (T) before and after indoor residual spraying (IRS) with DDT or pyrethroid (pyr)

\begin{tabular}{|c|c|c|c|c|c|c|}
\hline \multirow[t]{2}{*}{ Village } & \multicolumn{2}{|c|}{ Andranonahoatra } & \multicolumn{2}{|c|}{ Soanierana } & \multicolumn{2}{|c|}{ Analamiranga } \\
\hline & No. & PR (\%) & No. & PR (\%) & No. & PR (\%) \\
\hline Oct 02-Feb 03 (pre-IRS) & 377 & 86.4 & 241 & 90 & 629 & 87.5 \\
\hline Mar 03-May 03 (T1 DDT) & 68 & 75 & 263 & 82 & 1,042 & 85.6 \\
\hline Jun 03-Aug 03 (T2 DDT) & 22 & 95 & ND & ND & 460 & 96.5 \\
\hline Sept 03-Nov 03 (T3 DDT) & 16 & $12 / 16^{*}$ & 21 & 76 & 96 & 82.2 \\
\hline Dec 03-Feb 04 (T4 DDT) & 46 & 85 & 36 & 72 & 451 & 92.9 \\
\hline Mar 04-May 04 (T1 pyr) & 73 & 90 & 76 & 92 & 995 & 86.4 \\
\hline Jun 04-Aug 04 (T2 pyr) & 10 & $5 / 10^{*}$ & 24 & 92 & 499 & 94.9 \\
\hline Sept 04-Nov 04 (T3 pyr) & 23 & 87 & 20 & 95 & 109 & 93.5 \\
\hline Dec 04-Feb 05 (T4 pyr) & 50 & 94 & 27 & 89 & 378 & 92.0 \\
\hline Overall & 685 & 85.6 & 708 & 86.0 & 4,659 & 89.4 \\
\hline
\end{tabular}

$\mathrm{ND}=$ Not done *Parous rate not calculated when No. of nuliparous + parous mosquitoes $<25$.

when a threshold of 500 or 1,000 asexual parasites per ml of blood was introduced to define a malaria attack (results not shown).

\section{Discussion}

The present survey combines entomological and parasitological studies from the Malagasy Highlands and demonstrates the efficiency of IRS with DDT and IRS with pyrethroids (alphacypermethrin and deltamethrin) by analysing pre-and post-treatment data of two villages compared to a control village without intervention.

The entomological observations show the three anopheline species involved in the transmission of malaria on the Malagasy Central Highlands. An. funestus, An. arabiensis and $A n$. mascarensis were found infected. The prominent role of $A n$. funestus as vector of malaria parasites is highlighted. This species exhibits an intermediate behaviour endo-exophilic behaviour both for biting activity and resting. The indoor spraying with insecticide impacts its vectorial capacity. These observations claim for the sensitivity of An. funestus to used insecticides in the Central Malagasy highlands. An. arabiensis and An. mascarensis are secondary vectors and typically exophilic; indeed, most of those collected in this study were positive for zebu cattle blood. Consequently these anophelines are relatively less impacted by IRS. The degree in exophily appears linked to the degree in zoophily. However, the moderate impact of IRS with insecticide on the secondary vectors, if not ideal, does not render this vector control strategy ineffective as a great reduction in malaria transmission after IRS shows. Although, even with correct implementation, IRS with insecticide did not eliminate malaria transmission. This has been observed on many similar occasions $[4,11,19,20,26,32]$. The persistence of malaria vectors, with or without malaria cases, following an effective vector control measure is a known phenomenon since the 1960s [48].

The parasitological observations illustrate the prominent infection with $P$. falciparum in schoolchildren. In addition, three other malarial species are also prevalent, especially $P$. vivax. Despite a relatively low level of

Table 7 Number of anophelines positive for Plasmodium sp. in ELISA CSP, per village and vector species

\begin{tabular}{|c|c|c|c|c|c|}
\hline Village & & Andranonahoatra & Soanierana & Analamiranga & Total \\
\hline \multirow[t]{3}{*}{ P. falciparum } & An. funestus & 1 & 1 & 7 & 13 \\
\hline & An. arabiensis & 1 & 1 & 1 & \\
\hline & An. mascarensis & & 1 & & \\
\hline \multirow[t]{2}{*}{ P. vivax } & An. funestus & & & 6 & 7 \\
\hline & An. mascarensis & & & 1 & \\
\hline \multirow[t]{3}{*}{ Total } & An. funestus & 1 & 1 & 13 & 15 \\
\hline & An. arabiensis & 1 & 1 & 1 & 3 \\
\hline & An. mascarensis & & 1 & 1 & 2 \\
\hline Grand total & & 2 & 3 & 15 & 20 \\
\hline
\end{tabular}




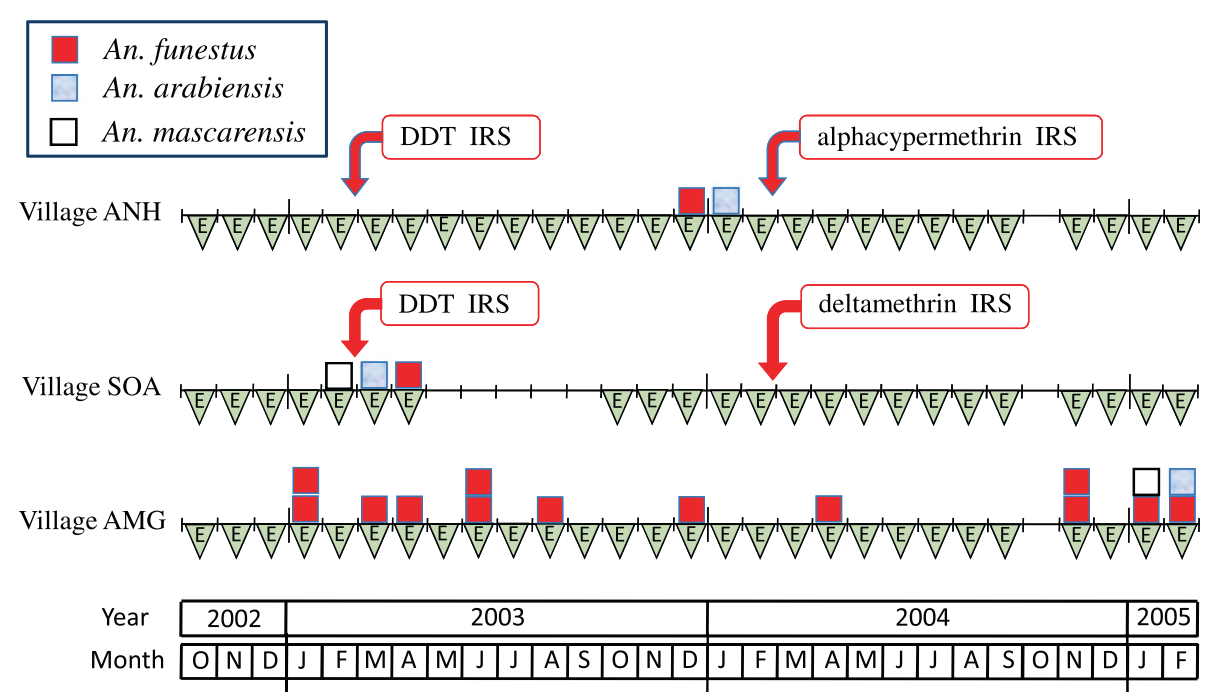

Figure 7 Distribution of the 20 anophelines ELISA-CSP positive for Plasmodium sp., belonging to 3 anopheles species, in the three villages. Indoor residual spray (IRS) with DDT and pyrethroids were performed in February 2003 and February 2004, respectively; the village AMG remained untreated.

malaria transmission (a daily EIR $=0.009$, as observed in the untreated village corresponds to an annual EIR = 3.3), positive parasitaemia was detected in schoolchildren suffering from uncomplicated simple malaria attacks. IRS with insecticide is rapidly followed by a reduction in prevalence of blood parasites and malaria attacks, both positive consequences. This has also been found elsewhere $[8,33,34,49]$.

These conclusions are reasonably robust. But some points can be discussed.

- The three studied communes are similar in surface area, climate, altitudinal elevation, human ethnic group, population density and agricultural activities. They also share a common border. In addition, the three studied villages are alike for human and zebu cattle population size, habitat, distance to running water, and elevation with regards to piedmont and rice field of sandbank. However noticeable differences were observed concerning entomological aspects such as relative proportions of anopheline species, unexplained increase in density (e.g. An. funestus in Soanierana but not in the two other villages the month following IRS with DDT) or decrease (e.g. An. mascarensis in the untreated Analamiranga in July-September 2004), and parasitological observations (e.g. the evolution of parasite ratio in the pre-treatment period in Andranonahoatra versus Soanierana). This set of uncontrolled intervariations arising between zones and proper environmental factors [28] limit comparisons between villages/communes. This constitutes an a posteriori confirmation of the relevance of our data processing which highlighted the evaluation before versus after the implementation of the control measures rather than an evaluation between communes/villages.

- As already stressed, the impact of IRS with insecticide is more effective on the endo-exophagic An. funestus than the exophagic An. arabiensis. Blood feeding behaviour and departure from houses were studied in Kenya under the impact of permethrin-impregnated eaves-sisal curtains: $A n$. funestus shifted to feeding more on cattle [50]. According to the present study, in Ethiopia, 1.5\% of outdoor-resting An. arabiensis and $66 \%$ of those collected indoors had fed on humans, and human baits outdoors caught $>2.5$ times more An. arabiensis than those indoors [51].

Table 8 Infectivity rate of anophelines and [confidence interval 95\%], per village and vector species

\begin{tabular}{lccc}
\hline Village & Andranonahoatra & Soanierana & Analamiranga \\
\hline An. funestus & $1 / 1,273=0.00079[0-0.00232]$ & $1 / 922=0.00108[0-0.00321]$ & $13 / 7,463=0.00174[0.00080-0.00269]$ \\
An. arabiensis & $1 / 3,256=0.00031[0-0.00091]$ & $1 / 3,032=0.00033[0-0.00098]$ & $1 / 1,274=0.00078[0-0.00232]$ \\
An. mascarensis & $0 / 332=0$ & $1 / 318=0.00314[0-0.00930]$ & $1 / 1,429=0.00070[0-0.00207]$ \\
\hline
\end{tabular}


Table 9 Daily entomological inoculation rate (EIR), per village and period before and after indoor residual spraying (IRS)

\begin{tabular}{ccccc}
\hline Period & Village & Andranonahoatra & Soanierana & Analamiranga \\
\hline pre-IRS & EIR An. funestus & 0 & 0 & 0.00422 \\
& EIR 3 vectors* & 0 & 0.00292 & 0.00422 \\
IRS DDT & EIR An. funestus & 0.00016 & 0.00145 & 0.00808 \\
& EIR 3 vectors* & 0.00044 & 0.00201 & 0.00808 \\
IRS pyrethroid & EIR An. funestus & 0 & 0 & 0.00954 \\
& EIR 3 vectors* & 0 & 0 & 0.01048 \\
\hline
\end{tabular}

*An. funestus + An. arabiensis + An. mascarensis.

- The general tendency for reduction of parasite prevalence in schoolchildren throughout the study was significant and expected. On the other hand a reduction of the parasite prevalence in the untreated commune of Maroharona remains partly unexplained; this may be a secondary effect of the presence/activity of the medical team in charge of the present study who provided anti-malarial drugs for treatment in cases of suspected malaria, in agreement with the national health policy.

- In the present study, 17 anophelines were detected positive with $P$. malariae and 13 with $P$. falciparum (Additional file 2: Table S2). In comparison, prevalences of these plasmodial species in children were $1.3 \%$ and $89.6 \%$, respectively; when looking at gametocyte prevalence the percentages were $0.6 \%$ [0.2\%-1.3\%] and $14.7 \%$ [CI 95\% = 12.6\%-17.0\%] (Additional file 1: Table S1). These observations are puzzling and question the true $P$. malariae infection of mosquitoes. The detection of infected mosquitoes was here performed using the ELISA, a technique known to produce false positives in the detection of circumsporozoite protein (CSP) in mosquitoes consequently of overestimating the infectivity rate [52-54]. Whatever is the cause of such overestimation, results on $P$. malariae infectivity of mosquitoes were not considered in the present study. Both infectivity rate and EIR were calculated on $P$. falciparum and $P$. vivax, two species that totalized $99 \%$ of Plasmodium infection in child population.

- By study design, the schoolchildren not present at school the day of the survey were not considered in the study. One may presume that a lot of sick children does not reach the school. On the contrary, because the date of the survey was announced in advance, the sick children went to school, sure to receive a free anti-malarial treatment. In other words, it is hard to know if the reported prevalence of malaria attacks in children at school is underestimated or not.

- Three insecticides were used, DDT, alphacypermethrin and deltamethrin. Overall, similar efficacies were recorded and thus each one can be applied indistinctly for malaria vector control in the highlands. Many entomological and parasitological variables were lower after IRS with pyrethroid than after IRS with DDT. This cannot be interpreted as a lower efficacy of DDT compared to pyrethroid for two reasons. First, the pyrethroids

Table 10 Plasmodic index (PI) and 95\% confidence interval $(\mathrm{CI})$, per commune

\begin{tabular}{|c|c|c|c|c|c|c|c|c|c|}
\hline \multirow{2}{*}{$\begin{array}{l}\text { Commune } \\
\text { Month }\end{array}$} & \multicolumn{3}{|c|}{ Ankadinondry-Sakay } & \multicolumn{3}{|c|}{ Mahasolo } & \multicolumn{3}{|c|}{ Maroharona } \\
\hline & No. & $\mathrm{PI} \%$ & $\mathrm{Cl} 95 \%$ & No. & $\mathrm{PI} \%$ & $\mathrm{Cl} 95 \%$ & No. & $\mathrm{PI} \%$ & $\mathrm{Cl} 95 \%$ \\
\hline Nov 02 & 227 & 7.5 & $4-12$ & 230 & 16.5 & $12-22$ & 223 & 24.2 & $19-30$ \\
\hline Feb 03 & 202 & 19.3 & $14-25$ & 215 & 14.4 & $10-20$ & 212 & 25.0 & $19-31$ \\
\hline May 03 & 201 & 19.9 & $15-26$ & ND & ND & ND & 215 & 57.7 & $51-64$ \\
\hline Sep 03 & 206 & 18.4 & $13-24$ & ND & $N D$ & ND & 205 & 54.6 & $48-62$ \\
\hline Nov 03 & 209 & 4.8 & $2-9$ & 202 & 10.4 & $7-15$ & 204 & 31.8 & $26-39$ \\
\hline Mar 04 & 202 & 11.9 & $8-17$ & 202 & 11.4 & $7-17$ & 203 & 38.9 & $32-46$ \\
\hline May 04 & 202 & 7.4 & $4-12$ & 202 & 8.4 & $5-13$ & 202 & 38.2 & $32-46$ \\
\hline Sep 04 & 200 & 5.0 & $2-9$ & 204 & 2.0 & $1-5$ & 204 & 27.0 & $21-34$ \\
\hline Feb 05 & 202 & 4.0 & $2-8$ & 200 & 2.5 & $1-6$ & 200 & 35.0 & $28-42$ \\
\hline Overall & 1851 & 10.9 & $9.5-12.3$ & 1455 & 9.5 & $10.0-11.0$ & 1868 & 36.9 & $34.7-39.1$ \\
\hline
\end{tabular}

$\mathrm{ND}=$ Not done. 


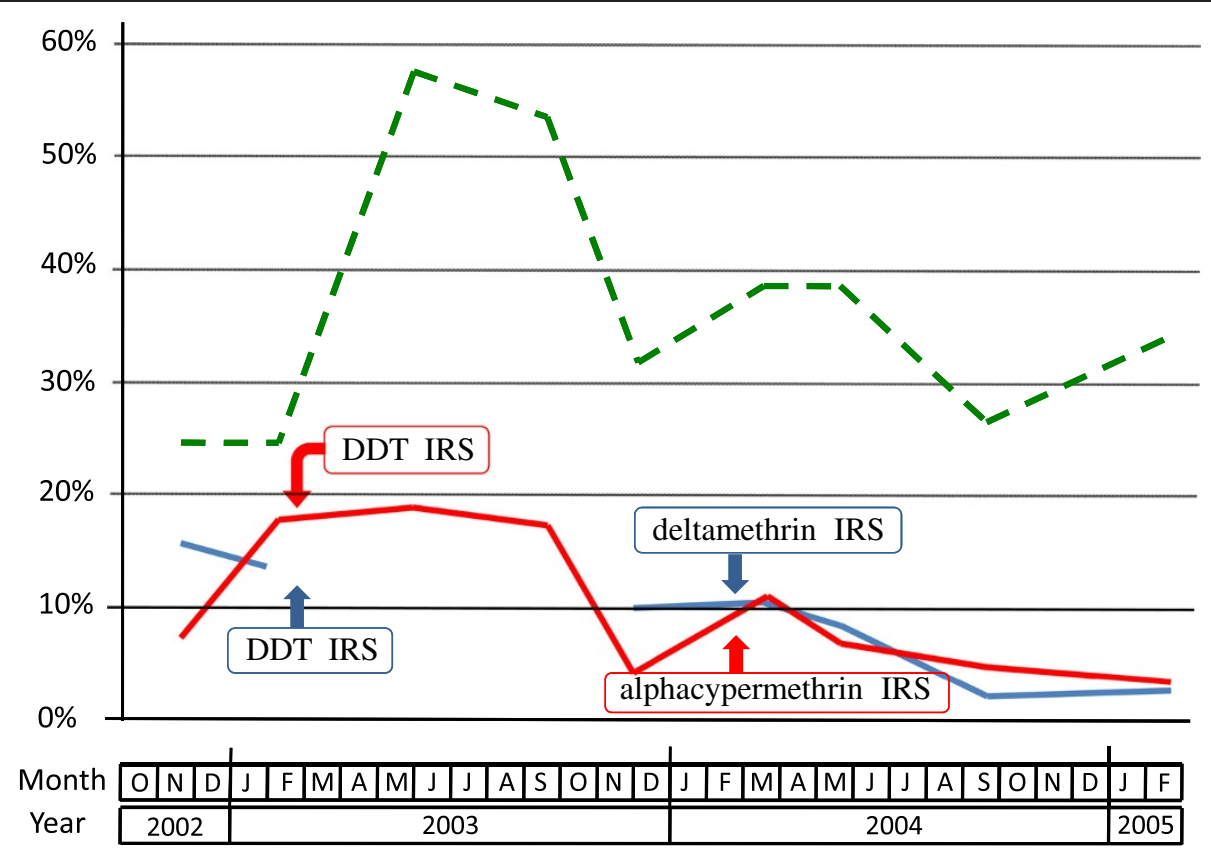

Figure 8 Plasmodic index in schoolchildren in the communes of Ankadinondry-Sakay (red line), Mahasolo (blue line), and Maroharona (green dashed line). Indoor residual spray (IRS) with DDT and pyrethroids were performed in February 2003 and February 2004, respectively; the Maroharona commune remained untreated.

were sprayed 12 months after DDT, in a time when the persistent effect of DDT was still partly effective on the house walls [49]. That is to say pyrethroids were probably not tested alone but with a small additive effect of DDT. Second, the reduction of plasmodic index and incidence of malaria attacks in 2004-05 in the untreated area impede to conclude for a better efficacy of pyrethroid by regard to DDT. Nevertheless the use of DDT was recently in the topic of discussion, especially when used in IRS in Africa [10-12].

Highlights can be raised for the future. Infected mosquitoes were collected in outside shelters, notably in the pit shelters that can be considered as the most 'outdoors' resting place examined. Insecticide spraying with insecticides outside houses could be useful, especially during malaria outbreaks or in the objective of the malaria eradication in Madagascar. Additionally, as the risk of re-invasion of vectors from untreated areas to treated areas is high [55,56], the level of IRS coverage is an important key points for efficient IRS.

Finally, this research project points out the fact that vector control per se will not reach achievement of elimination in area where the vectors exhibit a large spectrum of endo/exophilic behaviours in response to insecticide pressure. In order to reach the goal of pre-elimination there is also a need for rapid diagnostic of malaria parasites in humans and effective treatment. Such improvements are required for the next step of passing from pre-elimination to elimination phase in area where transmission still occurs. A transmission blocking vaccine could be one the needed new tools.

\section{Conclusions}

The results presented here suggest that a significant reduction of man-anopheline contact is possible, especially

Table 11 Median of densities (>0) of asexual P. falciparum (parasites $/ \mathrm{mm}^{3}$ of blood, log transformed) in schoolchildren, per commune

\begin{tabular}{|c|c|c|c|c|c|c|c|c|c|}
\hline \multirow{2}{*}{$\begin{array}{l}\text { Commune } \\
\text { Month }\end{array}$} & \multicolumn{3}{|c|}{ Ankadinondry-Sakay } & \multicolumn{3}{|c|}{ Mahasolo } & \multicolumn{3}{|c|}{ Maroharona } \\
\hline & No. & Median & P25-P75 & No. & Median & P25-P75 & No. & Median & P25-P75 \\
\hline Nov 02 and Feb 03 & 53 & 1059 & $433-3146$ & 59 & 471 & $96-971$ & 94 & 630 & $200-1243$ \\
\hline Overall & 174 & 329 & 80-1305 & 118 & 460 & $96-1081$ & 590 & 545 & $110-1524$ \\
\hline
\end{tabular}

P25-P75 = Percentiles 25 and 75. 
Table 12 Malaria attacks (axillary fever $>37^{\circ} \mathrm{C}$ plus asexual parasites in blood) of schoolchildren and $95 \%$ confidence interval $(\mathrm{Cl})$, per commune

\begin{tabular}{|c|c|c|c|c|c|c|c|c|c|}
\hline \multirow{2}{*}{$\begin{array}{l}\text { Commune } \\
\text { Month }\end{array}$} & \multicolumn{3}{|c|}{ Ankadinondry-Sakay } & \multicolumn{3}{|c|}{ Mahasolo } & \multicolumn{3}{|c|}{ Maroharona } \\
\hline & No. & $\%$ & $\mathrm{Cl} 95 \%$ & No. & $\%$ & $\mathrm{Cl} 95 \%$ & No. & $\%$ & $\mathrm{Cl} 95 \%$ \\
\hline Nov 02 & 6 & 2.6 & $0.5-4.7$ & 6 & 2.6 & $0.5-4.7$ & 30 & 13.4 & $8.9-17.9$ \\
\hline Feb 03 & 17 & 8.4 & $4.6-12.2$ & 10 & 4.7 & $1.9-7.6$ & 12 & 5.7 & $2.6-8.8$ \\
\hline May 03 & 15 & 7.5 & $3.8-11.2$ & ND & ND & ND & 70 & 32.6 & $26.3-38.9$ \\
\hline Sep 03 & 13 & 6.3 & $3.0-9.6$ & ND & ND & ND & 48 & 23.4 & $17.6-29.2$ \\
\hline Nov 03 & 6 & 2.9 & $0.6-5.2$ & 15 & 7.4 & $3.8-11.0$ & 49 & 24.0 & $18.1-29.9$ \\
\hline Mar 04 & 17 & 8.4 & $4.6-12.2$ & 12 & 5.9 & $2.7-9.1$ & 44 & 21.7 & $16.0-27.4$ \\
\hline May 04 & 9 & 4.4 & $1.6-7.2$ & 12 & 5.9 & $2.7-9.1$ & 43 & 21.3 & $15.7-27.0$ \\
\hline Sep 04 & 5 & 2.5 & $0.3-4.7$ & 2 & 1.0 & $0-2.4$ & 22 & 10.8 & $6.5-15.1$ \\
\hline Feb 05 & 6 & 3.0 & $0.6-5.4$ & 2 & 1.0 & $0-2.5$ & 19 & 9.5 & 5.4-13.6 \\
\hline Overall & 94 & 4.0 & $3.1-4.9$ & 59 & 4.0 & $3.0-5.0$ & 337 & 18.0 & $16.3-19.7$ \\
\hline
\end{tabular}

$\mathrm{ND}=$ Not done.

for An. funestus, the main vector in the Malagasy Highlands. In this region, the entomological inoculation rate is relatively low, about 3.3 bites of infected anophelines per man per year in the untreated village. The reduction of malaria transmission after IRS with insecticide, without additional control measures (like a better prevention, diagnostic, treatment, health services, etc.), is associated with a significant decrease in the prevalence of blood parasites and of malaria attacks in children. The reduction of risk was equivalent between IRS using pyrethroids and DDT, especially on vector biting and resting behaviour inside houses. The present study also shows that pyrethroids (alphacypermethrin and deltamethrin) are efficient alternatives to DDT when used in indoor residual spraying in the Highlands of Madagascar.

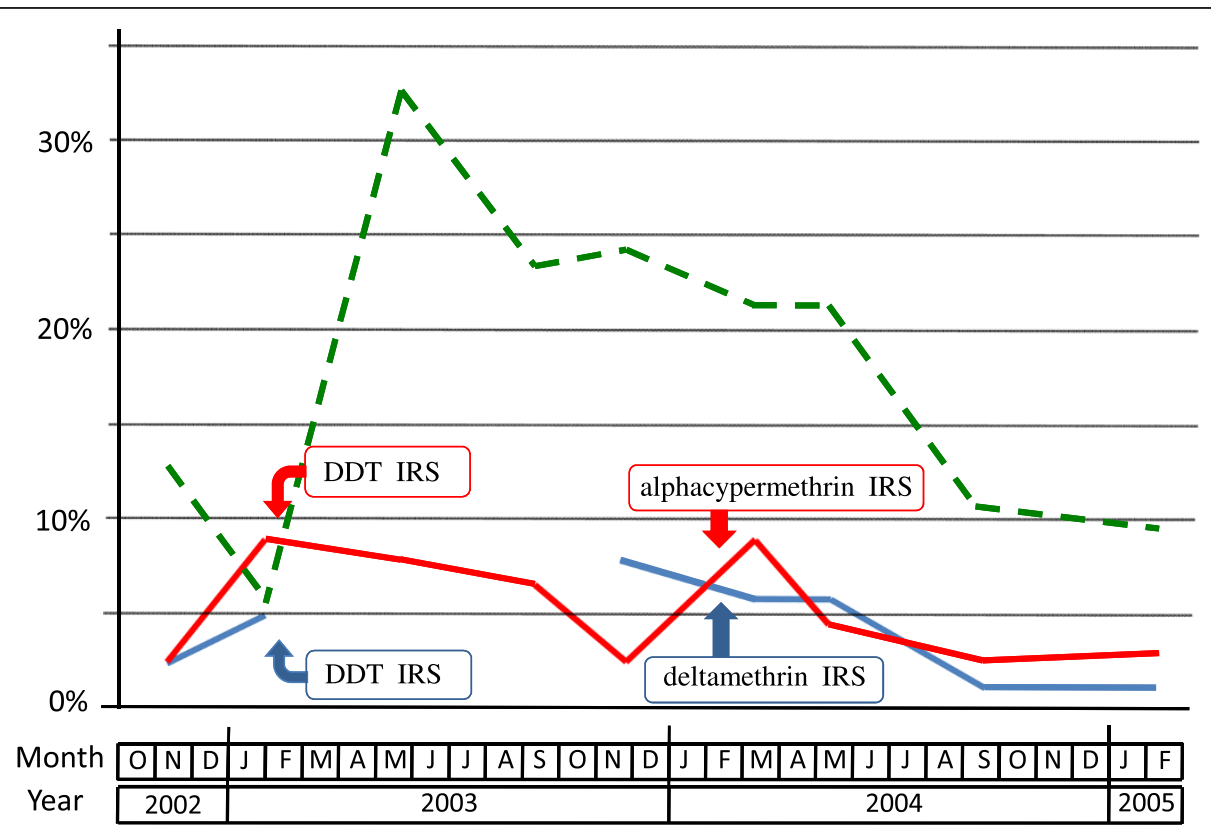

Figure 9 Prevalence of malaria attack (i.e. fever + asexual Plasmodium sp.) in schoolchildren in the communes of Ankadinondry-Sakay (red line), Mahasolo (blue line), and Maroharona (green dashed line). Indoor residual spray (IRS) with DDT and pyrethroids were performed in February 2003 and February 2004, respectively; the Maroharona commune remained untreated. 


\section{Additional files}

Additional file 1: Table S1. MahasoloParasito 2002-2005.xls. Crude demographic, parasitological and clinical data collected during the whole study. Each of the 5,174 lines concerns one schoolchild in the sheet 1 . The 34 columns are detailed in the sheet 2 .

Additional file 2: Table S2. MahasoloEntomo 2002-2005.xIs. Crude entomological data for the three malaria vectors collected during the whole study. Each of the 19,789 lines concerns one anopheline vector in the sheet 1 . The 15 columns are detained in the sheet 2 . The sampling effort is detailed in the sheet 3 .

\section{Competing interests}

The authors declare that they have no competing interests.

\section{Authors' contribution}

JR participated in the study design, data collection and data analysis; MER participated in the study design and supervised the IRS; MR and VaRa participated in the parasitological study; LA and GLG participated in the entomological study; CR and SB performed the statistical analysis. FA and ViRo conceived and coordinated the study. All authors participated in drafting the manuscript and approved the final manuscript.

\section{Acknowledgements}

We are grateful to the inhabitants of the studied area for their cooperation and members of the technical staff of Groupe de Recherche sur le Paludisme of the Institut Pasteur de Madagascar for their assistance. Doctor Philippe Mauclère, Director of the Institut Pasteur de Madagascar during the study, is warmly thanked. Authors are grateful to Doctor Katharina Kreppel for constructive comments she gave during write up of this manuscript. Doctor Karin Horn, head of vector control product development, Bayer environmental science, has given advice and support. This study was supported by the Ministry of Health and Family Planning of Madagascar via the World Bank project CRESAN.2 (3302-MAG), by the Institut Pasteur de Madagascar, by the Grand Programme Anopheles of the Institut Pasteur, by the Programme Pal + of the Ministère Français de la Recherche, by Bayer Environment Science, and by the Institut de Recherche pour le Développement.

\section{Author details}

'Institut Pasteur de Madagascar, Ambatofotsikely, BP 1274 Antananarivo 101, Madagascar. ${ }^{2}$ Ministère de la Santé, Programme National de Lutte contre le Paludisme, Androhibe, BP 8169 Antananarivo 101, Madagascar. ${ }^{3}$ MIVEGEC (Maladies Infectieuses et Vecteurs: Ecologie, Génétique, Evolution et Contrôle) UMR IRD 224, CNRS 5290, UM1, UM2, Centre IRD France-Sud, BP 64501, 34394 Montpellier Cedex 5, France. ${ }^{4}$ Unité de recherche Génétique et génomique des insectes vecteurs, Institut Pasteur de Paris, 25-28 rue du Dr Roux, 75015 Paris, France.

\section{Received: 16 August 2013 Accepted: 31 December 2013}

Published: 14 January 2014

\section{References}

1. Randriantsimaniry D: Lutte antivectorielle dans l'épidémie de paludisme des plateaux de Madagascar. Santé 1995, 6:392-396.

2. Curtis CF, Mnzava AEP: Comparison of house spraying and insecticide treated nets for malaria control. Bull World Health Organ 2000, 78:1389-1400.

3. Lumaret R: Etude sur le paludisme à Madagascar, situation en 1962. Antananarivo: Service Antipaludique, Rapport dactylographié; 1963:232.

4. Mouchet J, Carnevale P, Coosemans M, Julvez J, Manguin S, RichardLenoble D, Sircoulon J: Biodiversité du paludisme dans le monde. Montrouge: John Libbey Eurotext; 2004.

5. Fontenille D, Rakotoarivony I: Reappearance of Anopheles funestus as a malaria vector in the Antananarivo region, Madagascar. Trans $R$ Soc Trop Med Hyg 1988, 82:644-645.

6. Lepers JP, Fontenille D, Rason MD, Chougnet C, Astagneau P, Coulanges P, Deloron P: Transmission and epidemiology of newly transmitted falciparum malaria in the central highland plateaux of Madagascar. Ann Trop Med Parasitol 1991, 85:297-304.
7. Rakotomanana F, Jeanne I, Duchemin J, Pietra V, Raharimalala L, Tombo M, Ariey F: Approche géographique dans la lutte contre le paludisme dans la région des Hautes Terres Centrales à Madagascar. Arch Inst Pasteur Madagascar 2001, 67:27-30.

8. Romi R, Razaiarimanga MC, Raharimanga R, Rakotondraibe EM, Ranaivo LH Pietra V, Raveloson A, Majori G: Impact of the malaria control campaign (1993-1998) in the highlands of Madagascar: parasitological and entomological data. Am J Trop Med Hyg 2002, 66:75-82.

9. Banque mondiale, Direction des Opérations pour Madagascar, Comores, Maurice et Seychelles: Le partenariat Madagascar Banque Mondiale 2001/ 2002. 98. Available at www-wds.worldbank.org/servlet/WDSContentServer/ WDSP/IB/2003/01/17/000094946_03010704154242/Rendered/PDF/ multiOpage.pdf.

10. Chen A, Rogan WJ: Nonmalarial infant deaths and DDT use for malaria control. Emerg Infect Dis 2003, 9:960-964.

11. Sadasivaiah S, Tozan Y, Breman JG: Dichlorodiphenyltrichloroethane (DDT) for indoor residual spraying in Africa: how can it be used for malaria control? Am J Trop Med Hyg 2007, 77(Suppl.6):249-263.

12. Bouwman $\mathrm{H}$, van den Berg $\mathrm{H}$, Kylin $\mathrm{H}$ : DDT and malaria prevention: addressing the paradox. Environ Health Perspect 2011, 119:744-747.

13. WHO: Questions fréquemment posées à propos de l'utilisation du DDT pour la lutte antivectorielle, WHO/HTM/RBM/2004.54. Geneva: World Health Organization; 2005

14. Najera JA, Zaim M: Lutte contre les vecteurs du paludisme: Critères et procédures de prise de décision pour une utilisation raisonnée des insecticides. Geneva: World Health Organization; 2004. WHO_CDS_WHOPES_2002.5_Rev.1_Fre.pdf5.

15. Protopopoff N, Matowo J, Malima R, Kavishe R, Kaaya R, Wright A, West PA Kleinschmidt I, Kisinza W, Mosha FW, Rowland M: High level of resistance in the mosquito Anopheles gambiae to pyrethroid insecticides and reduced susceptibility to bendiocarb in north-western Tanzania. Malar J 2013, 12:149.

16. Chaccour CJ, Kobylinski KC, Bassat Q, Bousema T, Drakeley C, Alonso P, Foy $\mathrm{BD}$ : Ivermectin to reduce malaria transmission: a research agenda for a promising new tool for elimination. Malar J 2013, 12:153.

17. Fuchs S, Nolan T, Crisanti A: Mosquito transgenic technologies to reduce Plasmodium transmission. Methods Mol Biol 2013, 923:601-622.

18. Carter R: Spatial simulation of malaria transmission and its control by malaria transmission blocking vaccination. Int J Parasitol 2002, 32:1617-1624.

19. Padonou GG, Gbedjissi G, Yadouleton A, Azondekon R, Razack O, Oussou O, Gnanguenon V, Rock A, Sezonlin M, Akogbeto M: Decreased proportions of indoor feeding and endophily in Anopheles gambiae s l: populations following the indoor residual spraying and insecticide-treated net interventions in Benin (West Africa). Parasit Vectors 2012, 5:262.

20. Sharp BL, Ridl FC, Govender D, Kuklinski J, Kleinschmidt I: Malaria vector control by indoor residual insecticide spraying on the tropical island of Bioko: Equatorial Guinea. Malar J 2007, 6:52

21. Robert V, Groupe de Recherche sur le Paludisme: Evaluation des insecticides de remplacement du DDT dans les CAID (Campagnes d'Aspersion IntraDomiciliaire dinsecticide) sur les Hautes Terres Centrales de MadagascarPremier rapport comparant un traitement DDT à un témoin négatif dans le Moyen-Ouest (zone de Mahasolo) entre octobre 2002 et septembre 2003. Antananarivo: Institut Pasteur de Madagascar; 2003:62 002DocTech-IPM/2003.

22. Robert V, Groupe de Recherche sur le Paludisme: Evaluation des insecticides de remplacement du DDT dans les CAID (Campagnes d'Aspersion IntraDomiciliaire dinsecticide) sur les Hautes Terres Centrales de MadagascarDeuxième rapport comparant un traitement à l'alphacyperméthrine ou à la deltaméthrine à un témoin négatif dans le Moyen-Ouest (zone de Mahasolo) entre octobre 2003 et septembre 2004. Antananarivo: Institut Pasteur de Madagascar: 2005:71. 002DocTech-IPM/Entomo/2005.

23. Ratovonjato J, Rakotoson R: Evaluation de la rémanence des deux pyréthinoïdes: l'alphacyperméthrine 5\% et la deltaméthrine WG 250 de novembre 2004 à février 2005 dans le district de Tsiroanomandidy, Madagascar. Antananarivo: Institut Pasteur de Madagascar; 2007:27. 002DocTech-IPM/2007

24. Robert V, Le Goff G, Andrianaivolambo L, Randimby FM, Domarle O, Randrianarivelojosia M, Raharimanga V, Raveloson A, Ravaonjanahary C, Ariey F: Moderate transmission but high prevalence of malaria in Madagascar. Int J Parasitol 2006, 36:1273-1281. 
25. Grejbine A: Insectes Diptères Culicidae Anophelinae. Faune de Madagascar 1966, 22. Paris, ORSTOM CNRS.

26. Brutus L, Le Goff G, Rasoloniaina LG, Rajaonarivelo V, Raveloson A, Cot M: Lutte contre le paludisme dans le Moyen-Ouest de Madagascar: comparaison de l'efficacité de la lambda-cyhalothrin et du DDT en aspersions intra-domiciliaires: Il-Etude entomologique. Parasite 2001, 8:297-308.

27. Le Goff G, Randimby FM, Rajaonarivelo V, Laganier R, Leong Pock Tsy JM, Ceianu CS, Duchemin JB, Robert R: Anopheles mascarensis de Meillon 1947, vecteur de paludisme dans le Moyen-Ouest de Madagascar? Arch Inst Pasteur Madagascar 2003, 69:57-62.

28. Rajaonarivelo V, Le Goff G, Cot M, Brutus L: Les anophèles et la transmission du paludisme à Ambohimena, village de la marge occidentale des Hautes-Terres de Madagascar. Parasite 2004, 11:75-82.

29. Fontenille D, Lepers JP, Campbell GH, Coluzzi M, Rakotoarivony I, Coulanges $P$ : Malaria transmission and vector biology in Manarintsoa, high plateaux of Madagascar. Am J Trop Med Hyg 1990, 43:107-115.

30. Gillies MT, Coetzeee MC: A supplement to the Anophelinae of Africa south of the Sahara (Afrotropical region). Johannesburg: The South African Institute for Medical Research; 1987:143. n55.

31. Duchemin JB, Leong Pock Tsy JM, Rabarison P, Roux J, Coluzzi M, Costantini C: Zoophily of Anopheles arabiensis and A. gambiae in Madagascar demonstrated by odour-baited entry traps. Med Vet Entomol 2001, 15:50-57.

32. Albonico M, De Giorgi F, Razanakolona J, Raveloson A, Sabatinelli G, Pietra V, Modiano D: Control of epidemic malaria in the highlands of Madagascar. Parassitologia 1999, 41:373-376.

33. Cot M, Brutus L, Le Goff G, Rajaonarivelo V, Raveloson A: Lutte contre le paludisme dans le Moyen-Ouest de Madagascar: comparaison de l'efficacité de la lambda-cyhalothrin et du DDT en aspersions intradomiciliaires: II-Etude parasitologique et clinique. Parasite 2001, 8:309-316.

34. Jambou R, Ranaivo L, Raharimalala L, Randrianaivo J, Rakotomanana F, Modiano D, Pietra V, Boisier P, Rabarijaona L, Rabe T, Raveloson N, de Giorgi F: Malaria in the highlands of Madagascar after five years of indoor house spraying of DDT. Trans R Soc Trop Med Hyg 2001, 95:14-18.

35. WHO: Entomological field techniques for malaria control. Geneva: World Health Organization; 1992.

36. Muirhead-Thomson RC: A pit shelter for sampling outdoor mosquito population. Bull World Health Organ 1958, 19:241-261.

37. Scott JA, Brogdon WG, Collins FH: Identification of single specimens of the Anopheles gambiae complex by the polymerase chain réaction. Am J Trop Med Hyg 1993, 12:520-529.

38. Léong Pock Tsy JM, Duchemin JB, Marrama L, Rabarison P, Le Goff G, Rajaonarivelo $\mathrm{V}$, Robert $\mathrm{V}$ : Distribution of the species of the Anopheles gambiae complex, and first evidences of Anopheles merus as malaria vector in Madagascar. Malar J 2003, 2:33.

39. Detinova TS: Age-grouping methods in Diptera of medical importance with special reference to some vectors of malaria. Monogr Ser World Health Organ 1962, 47:13-191.

40. Beier JC, Perkins PV, Wirtz RA, Koros J, Diggs D, Gargan TP, Koech DK: Bloodmeal identification by direct-enzyme linked immunosorbent assay (ELISA), tested on Anopheles (Diptera: Culicidae) in Kenya. J Med Entomol 1988, 25:9-16.

41. Wirtz RA, Zavala F, Charoenvit Y, Campbell GH, Burkott TR, Schneir I, Esser $\mathrm{KM}$, Beaudoin RL, André RG: Comparative testing of monoclonal antibodies against Plasmodium falciparum sporozoites for ELISA development. Bull World Health Organ 1987, 65:39-45.

42. Andrianaivolambo L, Domarle O, Randrianarivelojosia M, Ratovonjato J, Le Goff G, Talman A, Ariey F, Robert V: Anthropophilic mosquitoes and malaria transmission in the eastern foothills of the central highlands of Madagascar. Acta Trop 2010, 116:240-245.

43. WHO: Terminology of malaria and malaria eradication: technical report. Geneva: World Health Organization; 1963.

44. Basseri $H$, Raeisi A, Khakha MR, Pakarai A, Abdolghafar H: Seasonal abundance and host-feeding patterns of anopheline vectors in malaria endemic area of Iran. J Parasitol Res 2010, 2010:671291.

45. Pappa V, Reddy M, Overgaard HJ, Abaga S, Caccone A: Estimation of the human blood index in malaria mosquito vectors in Equatorial Guinea after indoor antivector interventions. Am J Trop Med Hyg 2011, 84:298-301.
46. Gruchet H: Etude de l'âge physiologique des femelles d'Anopheles funestus funestus Giles dans la région de Miandrivazo, Madagascar. Bull Soc Path Exot 1962, 55:165-174.

47. Boisier P, Jambou R, Raharimalala L, Roux J: Relation between parasite density and fever risk in a community exposed to low level of malaria transmission in Madagascar highlands. Am J Trop Med Hyg 2002, 67:137-140

48. Taufflieb R, Saugrain J: Anophélisme sans paludisme au Nord du Tchad. Bull Soc Pathol Exot 1960, 2:150-152.

49. Groupe de Recherche sur le Paludisme: Atlas évolutif du paludisme à Madagascar. Antananarivo: Institut Pasteur de Madagascar; 2002:33.

50. Githeko AK, Adungo NI, Karanja DM, Hawley WA, Vulule JM, Seroney IK, Ofulla AV, Atieli FK, Ondijo SO, Genga IO, Odada PK, Situbi PA, Oloo JA: Some observations on the biting behavior of Anopheles gambiae s.s., Anopheles arabiensis and Anopheles funestus and their implications for malaria control. Exp Parasitol 1996, 82:306-315.

51. Tirados I, Costantini C, Gibson G, Torr SJ: Blood-feeding behaviour of the malarial mosquito Anopheles arabiensis: implications for vector control. Med Vet Entomol 2006, 20:425-437.

52. Durnez L, Van Bortel W, Denis L, Roelants P, Veracx A, Trung HD, Sochantha $T$, Coosemans M: False positive circumsporozoite protein ELISA: a challenge for the estimation of the entomological inoculation rate of malaria and for vector incrimination. Malar J 2011, 10:195

53. Fontenille D, Meunier JY, Nkondjio CA, Tchuinkam T: Use of circumsporozoite protein enzyme-linked immunosorbent assay compared with microscopic examination of salivary glands for calculation of malaria infectivity rates in mosquitoes (Diptera: Culicidae) from Cameroon. J Med Entomol 2001, 38:451-454.

54. Lochouarn L, Fontenille D: ELISA detection of malaria sporozoites: false-positive results in Anopheles gambiae s.l. associated with bovine bloodmeals. Trans R Soc Trop Med Hyg 1999, 93:101-102.

55. Ayala D, Le Goff G, Robert V, De Jong P, Takken W: Population structure of the malaria vector Anopheles funestus (Diptera: Culicidae) in Madagascar and Comoros. Acta Trop 2006, 97:292-300.

56. Randrianarivelojosia M, Raveloson A, Randriamanantena A, Juliano رل Andrianjafy T, Raharimalala LA, Robert V: Lessons learnt from the six decades of chloroquine use (1945-2005) to control malaria in Madagascar. Trans R Soc Trop Med Hyg 2009, 103:3-10.

doi:10.1186/1475-2875-13-21

Cite this article as: Ratovonjato et al:: Entomological and parasitological impacts of indoor residual spraying with DDT, alphacypermethrin and deltamethrin in the western foothill area of Madagascar. Malaria Journal 2014 13:21.

\section{Submit your next manuscript to BioMed Central and take full advantage of:}

- Convenient online submission

- Thorough peer review

- No space constraints or color figure charges

- Immediate publication on acceptance

- Inclusion in PubMed, CAS, Scopus and Google Scholar

- Research which is freely available for redistribution 